\title{
Treatment of Dystonia: Medications, Neurotoxins, Neuromodulation, and Rehabilitation
}

\author{
Ian O. Bledsoe ${ }^{1}$ (D) Aaron C. Viser ${ }^{1} \cdot$ Marta San Luciano $^{1}$ \\ Accepted: 4 October 2020 / Published online: 23 October 2020 \\ (C) The American Society for Experimental NeuroTherapeutics, Inc. 2020
}

\begin{abstract}
Dystonia is a complex disorder with numerous presentations occurring in isolation or in combination with other neurologic symptoms. Its treatment has been significantly improved with the advent of botulinum toxin and deep brain stimulation in recent years, though additional investigation is needed to further refine these interventions. Medications are of critical importance in forms of dopa-responsive dystonia but can be beneficial in other forms of dystonia as well. Many different rehabilitative paradigms have been studied with variable benefit. There is growing interest in noninvasive stimulation as a potential treatment, but with limited long-term benefit shown to date, and additional research is needed. This article reviews existing evidence for treatments from each of these categories. To date, there are many examples of incomplete response to available treatments, and improved therapies are needed.
\end{abstract}

Key Words Dystonia $\cdot$ botulinum toxin $\cdot$ neuromodulation $\cdot$ deep brain stimulation $\cdot$ rehabilitation

\section{Introduction}

Dystonia is a heterogeneous disorder with many etiologies, varied clinical presentations, and diverse treatment responses. Despite the considerable progress in our understanding of this condition, disease-modifying therapies do not exist for most dystonia types. However, the symptomatic treatment of dystonia has improved markedly since the introduction of botulinum toxin (BoNT) and deep brain stimulation surgery (DBS).

Treatments for dystonia must be individualized and tailored to each patient with attention to the patient's age, anatomic distribution of dystonic symptoms, and the potential risk for adverse effects. Treatments may aim to improve abnormal movements, postures, and discomfort as well as

Ian O. Bledsoe

Ian.Bledsoe@ucsf.edu

Aaron C. Viser

Aaron.Viser@ucsf.edu

Marta San Luciano

Marta.SanLucianoPalenzuela@ucsf.edu

1 Weill Institute for Neurosciences, Movement Disorder and Neuromodulation Center, University of California, San Francisco, 1635 Divisadero St., Suite 520, San Francisco, CA 94115, USA to manage comorbidities such as mood disorders, contractures, and orthopedic complications. While a robust evidence base is growing in some areas of dystonia therapeutics, including deep brain stimulation and some aspects of neurotoxin treatment, there are notable gaps in welldesigned and controlled trials in other areas. Some of the challenges in designing trials in dystonia include a limited ability of clinical scales to capture true functional change of therapies in some dystonia subtypes and the large heterogeneity in etiology and clinical features of different forms of dystonia. Many studies are uncontrolled, present only short-term follow-up information, and may have relatively small sample sizes.

In this review, we will outline the few available pathogenesis-targeted therapies for specific dystonic disorders and will describe the current symptomatic pharmacologic options for treatment of dystonia. We will discuss the current use of BoNT which revolutionized the treatment of dystonia when it was introduced into clinical practice in the late 1980s. We will also review evidence from ablative surgical procedures and deep brain stimulation trials, as advances in functional stereotactic neurosurgery over the past three decades have markedly widened the scope of dystonia treatment. Finally, we will provide an overview of evidence for other interventions including various rehabilitative paradigms and noninvasive stimulation techniques. 


\section{Pathogenesis-Targeted Therapy}

Mechanism-based treatments capable of modifying disease course and improving outcomes exist for only a small heterogeneous group of rare inherited neurological disorders affecting primarily children. Movement disorders, particularly complex dystonia, are relatively common manifestations of these disorders. Two of the best-known examples include doparesponsive dystonia (DRD) and Wilson's disease. Since these diseases are rare, much of the evidence for treatment comes from small studies, mostly single arm, unblinded, and nonrandomized [1]. In some cases, such as levodopa in DRD, treatments have become standard of care without approval from regulatory agencies, and treatment recommendations are mostly based on consensus opinion and principles of good clinical practice. For many of these disorders, early diagnosis and treatment are paramount to prevent disease progression and permanent neurological damage. A recent review by Jinnah et al. from 2018 summarizes many of these disorders with a comprehensive overview of their treatments such as enzyme replacement therapies, dietary modifications, and other targeted therapies [2]. Although it is beyond the scope of this current review to provide detailed therapeutic algorithms for these disorders, a summary table of the most common disorders primarily manifesting with dystonia is provided (Table 1), and we will briefly discuss Wilson's disease and DRD.

Dopa-responsive dystonia represents the best example of a targeted mechanistic therapy in dystonia. DRD encompasses several clinically and genetically heterogeneous conditions caused by various defects in dopamine biosynthesis that result in childhood or early adulthood progressive dystonia, but also parkinsonism and spasticity, and which often show marked improvement with levodopa treatment [19]. One form of DRD, known as Segawa's disease, is related to deficiencies in GTP-cyclohydrolase 1 (GTP-CH-1) caused by autosomal dominant or recessively inherited pathogenic variants in the GCH1 gene [20,21]. A second form is caused by a deficiency of sepiapterin reductase [22] and results from autosomal recessive variants in SPR [23] which lead to disruption of the biosynthesis of tetrahydrobiopterin (BH4), an essential cofactor for tryptophan hydroxylase and phenylalanine hydroxylase. A third relates to deficiencies in tyrosine hydroxylase [14] (TH) caused by autosomal recessive variants in $T H$ which disrupts dopamine synthesis in its initial and rate-limiting step [13]. 6-Pyruvol-tetrahydropterin (PTP) synthase encoded by $P T S$ [17] and dihydropteridine reductase (DHPR) encoded by $Q D P R[17,18]$ are also involved in the synthesis and regeneration of $\mathrm{BH} 4$, and their rare deficiency can result in a DRD phenotype that includes symptoms beyond dystonia [24]. The aromatic L-amino acid decarboxylase (AADC) is the final enzyme in the biosynthesis of dopamine and serotonin. Its deficiency results in a rare autosomal recessive neurometabolic disorder with a combined deficiency of serotonin, dopamine, norepinephrine, and epinephrine, which is associated with an early presentation that includes generalized dystonia [12].

When initiated early, treatment with levodopa combined with a peripheral decarboxylase inhibitor (and/or BH4 in certain cases) can prevent the onset and progression of DRD-like symptoms [13]. Patients with autosomal dominant GTP-CH-I deficiency usually have an excellent and sustained response to low doses of levodopa, with minimal wearing off or levodopainduced dyskinesia. Those with autosomal recessive or compound heterozygous GTP-CH-I deficiencies may require higher doses, though still typically have adequate and sustained responses $[18,25,26]$. These patients may require additional treatment with BH4 and 5-hydroxytryptophan (5HT) $[18,26]$. Despite dramatic improvements with levodopa, residual symptoms even in autosomal dominant GTP-CH-I deficiency are not uncommon [27] and may require additional treatments $[26,28]$ including anticholinergic medications, dopamine agonists, botulinum toxin injections, or even DBS surgery [29]. Tyrosine hydroxylase and sepiapterin reductase deficiencies can also have a good response to levodopa but the response may be delayed or incomplete and is commonly associated with levodopa-induced dyskinesia, especially in TH deficiency $[14,16,26,30]$. The pathophysiological basis of dyskinesia seen in DRD is unclear [13], but is thought to be unrelated to neurodegeneration and striatal denervation (in distinction from that seen in Parkinson's disease) [30]. A marked and sustained positive response to levodopa without levodopa-induced dyskinesia is described in PTP synthase deficiency, though its use is frequently in combination with BH4 and 5-HT. These patients also tend to display other neurological symptoms including early childhood seizures, spasticity, and cognitive deficits $[15,24,26]$. Motor outcomes for those with TH, PTP synthase, DHPR, and autosomal recessive GTP-CH-I deficiencies are less favorable compared to those with sepiapterin or autosomal dominant GTP-CH-I deficiencies [26]. For patients with AADC deficiency, dopamine agonists combined with monoamine oxidase inhibitors (MAOIs) constitute the most common therapeutic approach, and levodopa is less commonly used [12]. These patients generally have very limited success with treatment [26], but gene therapy has recently shown some promising results [31]. Interestingly, there is some evidence of genotype/treatment interactions since certain $A A D C$ variants that affect levodopa binding sites tend to show a better response to treatment [12].

Wilson's disease is caused by autosomal recessively inherited pathogenic variants in the $A T P 7 B$ gene, encoding a copper-transporting P-type ATPase [32]. It is associated with a variety of movement disorders, frequently including dystonia [4]. The treatment of Wilson's disease includes copper chelation (with penicillamine, trientine, or tetrathiomolybdate) and/or zinc treatment to reduce intestinal copper uptake, as 


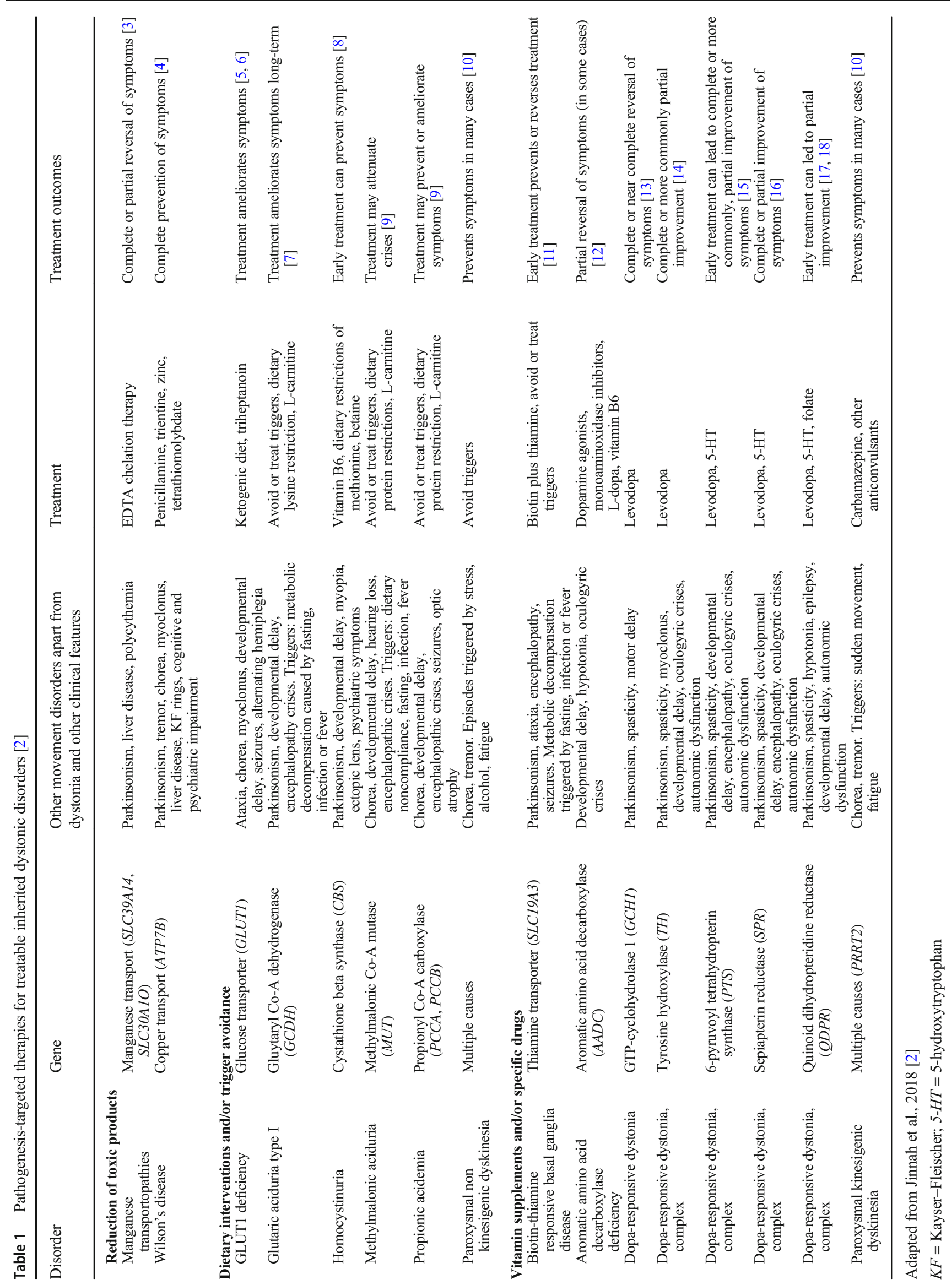


well as following a low-copper diet [4]. Early treatment likely prevents neurological injury [33]. Chelation of heavy metals using intravenous disodium calcium edetate (EDTA) is used in the more recently described inherited manganese transportopathies, conditions that primarily present with progressive complex dystonia. These include hypermanganesemia with dystonia 1 and hypermanganesemia with dystonia 2, related to defects in the SLC3OA10 and SLC39A14 genes respectively [3].

\section{Symptomatic Treatments}

\section{Medication Therapy}

Pharmacological treatments in dystonia include dopaminergic, antidopaminergic, and anticholinergic therapies, baclofen, benzodiazepines, muscle relaxants, dopamine depleters (VMAT-2 inhibitors), and others [34]. For many medications, pharmacological treatment is based largely on empirical experience rather than scientific rationale given the limited study of their use in dystonia $[35,36]$. Unfortunately, many patients with dystonia require a combination of oral medications or other treatments and the number of patients who fail medical treatment altogether is high due to lack of benefit or poor tolerability, especially when using high doses of anticholinergic drugs in adults [35].

\section{Dopaminergic and Antidopaminergic Medications}

Apart from DRD, levodopa and other dopaminergic treatments have been used symptomatically in other types of dystonia, including acquired forms [37], myoclonus-dystonia, and rapid-onset dystonia-parkinsonism (RDP) [38]. The mechanism of action of levodopa in dystonia other than DRD remains poorly understood, and generally, the response is not nearly as robust as in DRD.

Myoclonus-dystonia is characterized by early-onset dystonia and myoclonus and is often responsive to alcohol [39]. Most cases are related to mutations in the epsilonsarcoglycan gene (SCGE) [39]. Adequate and sustained response to levodopa in this condition has been described [40], though successful treatment usually involves other medications such as benzodiazepines, valproate, levetiracetam, L$5 \mathrm{H}$-tryptophan, and rarely sodium oxybate [41]. Improvement with DBS is well documented [42].

RDP, designated as DYT12, is characterized by the rapid development of focal, segmental, or hemibody dystonia primarily affecting cranial regions and upper limbs, and is caused by defects in the $\mathrm{Na}^{+} / \mathrm{K}^{+}$-ATPase alpha3 gene, ATP1A3 [43]. The phenotype of ATP1A3 defects is broad and can include bulbar symptoms, parkinsonism, seizures, alternating hemiplegia, and psychiatric features. With rare exceptions [44,
45], most patients are unfortunately unresponsive or minimally responsive to levodopa [43]. Side effects of levodopa include nausea and vomiting, orthostatic hypotension, and psychosis.

First-generation dopamine agonists such as apomorphine, bromocriptine, and lisuride, rarely used clinically now, showed positive responses in small trials in dystonia [46]. Of possible relevance to the positive response to dopaminergic treatment seen in some forms of dystonia, a recent study of a mouse model of generalized dystonia suggests that potentiating dopamine neurotransmission through coactivation of D1 and D2 receptors may be an effective strategy for the treatment of dystonia [47].

In the past, dopamine receptor-blocking medications were used extensively to treat dystonia [46, 48-51]. Their use is nonetheless controversial and currently discouraged because of their uncertain efficacy [49-51] and extensive side effect profile, including the potential development of tardive syndromes $[35,52]$. One exception is clozapine, a D4 receptor blocker (with relative sparing of D2 receptors), a drug that generally does not carry a significant risk of parkinsonism or tardive syndromes. Clozapine requires frequent blood draws to monitor for agranulocytosis but has shown efficacy in addressing tardive syndromes [49, 52, 53].

\section{VMAT-2 Inhibitors for Tardive Dystonia}

The treatment of tardive dystonia has shifted since the introduction and widespread use and success of vesicular monoamine transporter-2 (VMAT2) inhibitors. The first use of tetrabenazine (TBZ) for dystonia and other hyperkinetic movement disorders dates back to the 1970s [54]. TBZ is rarely used currently as a first-line agent in dystonia, except in tardive cases [34]. Available in the USA since 2008, TBZ remains FDA approved only for the management of Huntington's disease-related chorea [55], and its use in tardive dystonia is considered off-label. Observational studies and small trials support a beneficial effect in tardive dystonia [56]. Reserpine, a related catecholamine and 5hydroxytryptamine depleter used in the past for tardive syndromes, is limited by hypotension and high risk of depression [34] and is no longer available in the USA. More recently, two novel VMAT2 inhibitors, deutetrabenazine and valbenazine, have become available and show improved pharmacodynamic and pharmacokinetic profiles over TBZ [57]. Both medications have shown efficacy in double-blind, randomized, placebo-controlled trials (DBRPCTs) and were FDA approved for the treatment of tardive dyskinesia in 2017. Deutetrabenazine, a deuterated version of TBZ, has been evaluated in 2 DBRPCTs [58, 59] and one open-label study [60]. Valbenazine, a highly selective reversible VMAT-2 inhibitor consisting of 3 oxidative TBZ metabolites, has been evaluated in 4 DBRPCTs [61-64] and one open-label study [65]. Taken 
together, trials for these two drugs enrolled over 1000 patients, including those with tardive dystonia, representing the largest controlled drug trials in tardive hyperkinetic movement disorders to date. A recent meta-analysis of all the DBRPCTs confirmed the efficacy of VMAT-2 inhibitors for tardive dyskinesia as measured by the Abnormal Involuntary Movement Scale (AIMS) and found no increased risk of adverse effects versus placebo [66]. There are, however, no head-to-head comparisons between VMAT-2 inhibitors and other agents. An open-label study currently underway aims to evaluate deutetrabenazine specifically in dystonia (Table 2).

\section{Anticholinergic Medications}

These medications, considered to be among the most effective pharmacological agents for dystonia, are used predominately to treat generalized dystonia but have been shown to benefit other forms as well [35]. Trihexyphenidyl is the most commonly prescribed medication of this class, but benztropine, ethopropazine, procyclidine, and biperiden have all been used [34]. Diphenhydramine, a histamine H1 antagonist with anticholinergic properties, has also shown antidystonic effects in a small trial [67]. Efficacy of anticholinergic drugs in dystonia is thought to relate to effects on hyperactivity of striatal cholinergic interneurons $[68,69]$.

Trihexyphenidyl, used since the early 1950s [70], showed a significant benefit in 22 of 31 adult and pediatric dystonia patients in a crossover DBRPCT in 1986 (doses up to $120 \mathrm{mg} /$ day), and $42 \%$ continued to show a considerable dramatic benefit more than 2 years later [71]. An earlier openlabel study in 75 patients showed that high dose trihexyphenidyl and ethopropazine improved dystonic symptoms in $61 \%$ of children and $38 \%$ of adults [72]. Ethopropazine is not currently available in the USA. Autonomic side effects of blurred vision from mydriasis, constipation, dry mouth, and urinary retention may be relieved by pyridostigmine, pilocarpine eye drops, cevimeline, or synthetic saliva [35]. Central side effects, however, including sedation, confusion, mental fogginess, psychosis, and chorea, can be mitigated only with a decrease in dose, limiting the use of anticholinergics. Children generally tolerate much higher doses than adults [73], but school performance should be closely watched. Slow titration is recommended, from $1 \mathrm{mg}$ twice daily to doses as high as $80-100 \mathrm{mg} /$ day divided into three doses as tolerated. These higher doses are typically tolerated only in children [35].

\section{Baclofen and Benzodiazepines}

Oral baclofen, a $\mathrm{GABA}_{\mathrm{B}}$ autoreceptor agonist used primarily in spasticity, is considered by some as the next most effective agent [35], though there have been no controlled trials of baclofen or benzodiazepines in dystonia [34]. GABA, an inhibitory neurotransmitter, plays an integral role in basal ganglia circuitry, and impaired GABA control leading to sensorimotor disinhibition may play a role in dystonia [74].

Open-label and anecdotal data support a beneficial effect of oral baclofen. A retrospective study in 1988 involving 108 patients showed $20 \%$ with adequate response to an average maximum daily dose of $82 \mathrm{mg}$ (range $25-120 \mathrm{mg}$ ) over an average duration of therapy of 21 months [75]. In a small case series from 1992, 44\% of children with idiopathic dystonia treated with baclofen had sustained beneficial effects [76], with improved responses in those with shorter disease duration. Two other reports have documented improved symptoms with baclofen in tardive dystonia [77] and in a patient with Meige syndrome in combination with valproic acid [78]. Side effects from baclofen include nausea, drowsiness, and dizziness, and excessive reductions in muscle tone may occur. Abrupt discontinuation may result in the potentially lifethreatening baclofen withdrawal syndrome.

Following its success in treating spasticity related to spinal cord injury, intrathecal baclofen (ITB) was utilized for the first time in dystonia in 1991 to treat an 18-year-old man who developed refractory axial dystonia after spinal surgery [79]; its use was reported subsequently in dystonic cerebral palsy [80]. Walker et al. reported the effectiveness of ITB in 14 patients with isolated and acquired dystonia, 5 of whom showed objective benefit on blinded scales (mean duration of follow-up 29 months, mean dose $590 \mu \mathrm{g} /$ day, range 50 $1000 \mu \mathrm{g} /$ day) [81]. The response to oral baclofen did not predict the response to ITB. Hou et al. reported an additional 10 patients with severe segmental or generalized dystonia treated with ITB (mean duration of follow-up 4.7 years) of whom five had marked improvement, four had mild to moderate improvement, and one had the pump removed [82]. Those with concomitant spasticity and trunk and lower limb involvement appeared to benefit the most. In the largest published series of ITB for severe generalized dystonia including 86 patients ( $71 \%$ secondary to cerebral palsy), pumps were implanted after successful bolus injections in 77 patients. Decreased dystonia severity scores and improved quality of life were shown, with $92 \%$ retaining their beneficial responses at a median follow-up time of 29 months [83].

ITB is currently recommended for patients with refractory combined dystonia and spasticity predominately affecting the trunk and lower limbs. Before pump placement, most patients undergo a trial dose of ITB to assess their expected response. The most common complications of ITB include constipation, decreased neck and trunk control, and drowsiness. Surgical and hardware-related complications including pump malfunction and infection are unfortunately common $[34,35,83]$.

Intraventricular baclofen (IVB) may be an alternative to ITB in those patients with refractory dystonia who are not adequate candidates for ITB, or those requiring multiple revisions of ITB pumps $[84,85]$. The largest reported case series 

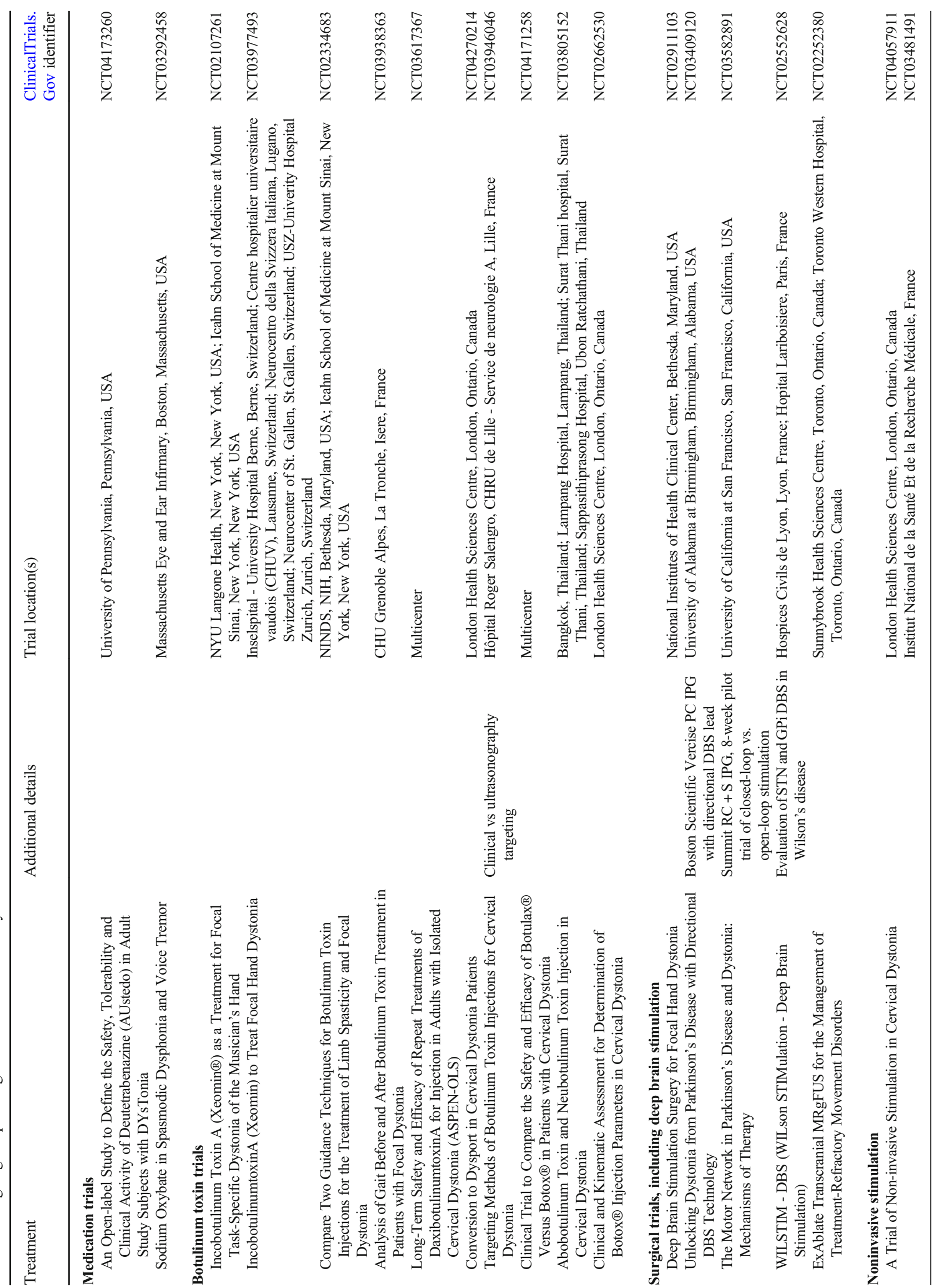


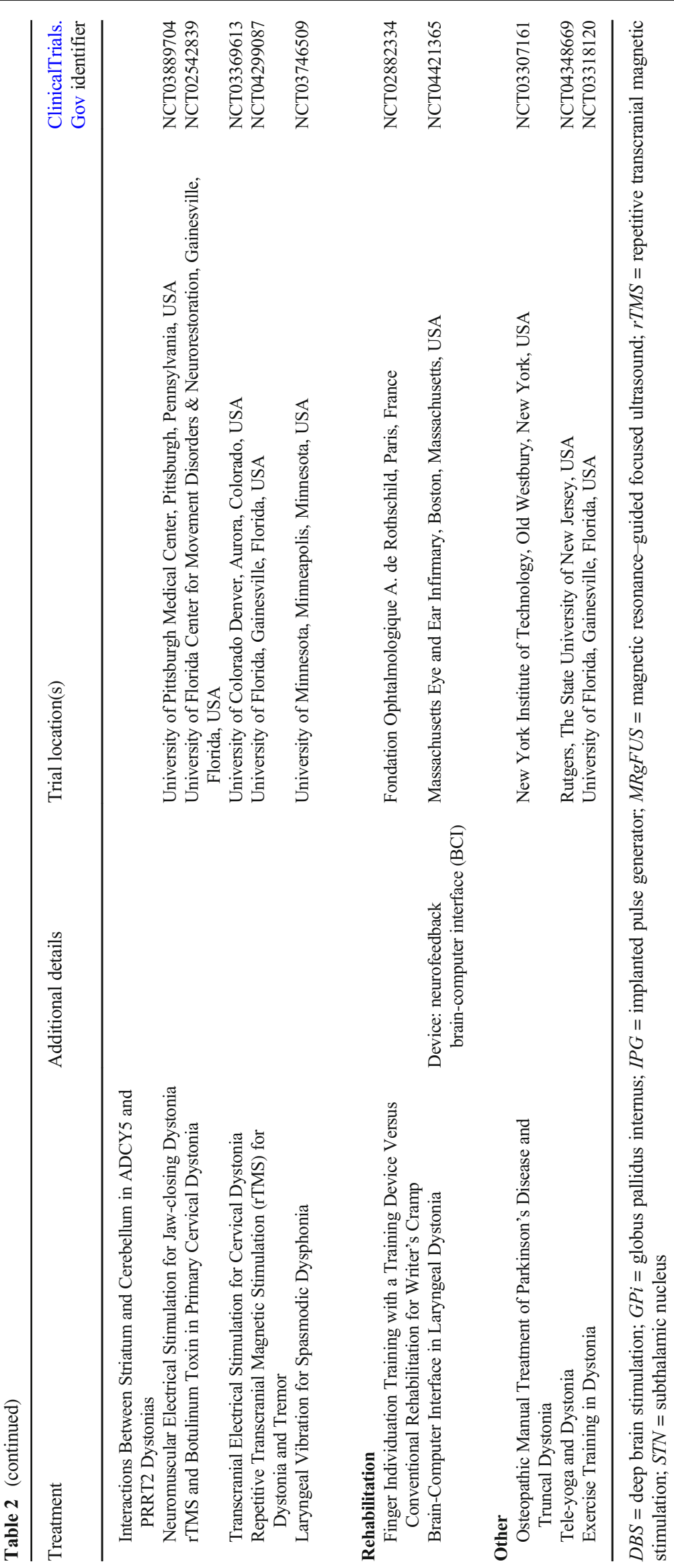


included 20 patients treated with IVB after increasing revision requirements during ITB therapy. IVB was associated with a lower revision and complication rate [85].

Benzodiazepines, including diazepam, clonazepam, and lorazepam are considered to be second or third-line agents in the management of dystonia [34]. Benzodiazepines bind to $\mathrm{GABA}_{\mathrm{A}}$ receptors and increase the opening frequency of a chloride channel, which facilitates inhibitory signals. Clonazepam and diazepam are preferred given their longer half-life but no head-to-head comparisons exist. In a retrospective open-label study of 115 patients, the average maximum dose of clonazepam for those with a good response was $3.7 \mathrm{mg} /$ day. Best responses were achieved in acquired dystonia, but in most patients, anticholinergics were more effective [75]. Benefit in acquired hemidystonia has been reported [86], and clonazepam may be particularly helpful in myoclonusdystonia [35]. Side effects include somnolence, dizziness, ataxia, fatigue, depression and behavioral abnormalities, and abrupt discontinuation may lead to a life-threatening withdrawal syndrome.

\section{Other Medications and New Developments}

Muscle relaxants used in dystonia include cyclobenzaprine, tizanidine, metaxalone, carisoprodol, methocarbamol, orphenadrine, and chlorzoxazone [34, 35], with evidence for their use derived only from anecdotal use or case reports.

Zolpidem, FDA approved in 1992 for short-term treatment of insomnia, is a nonbenzodiazepine imidazopyridine $\mathrm{GABA}_{\mathrm{A}}$ receptor modulator with a high affinity for the GABA-benzodiazepine subtype receptor BZ1 present in the basal ganglia. Following reports of its use resulting in motor benefits in parkinsonism [87], zolpidem was reported to improve cranial symptoms in Meige syndrome [88] and dystonic symptoms by an average of 54\% in three patients with Lubag dystonia (X-linked dystonia-parkinsonism, DYT3) [89]. An open-label study in 2012 in 34 patients with diverse dystonia types (average dose $8-12 \mathrm{mg} /$ day, range 5-20 mg/day) showed lower dystonia severity scores after treatment, with improvement comparable to trihexyphenidyl [90]. Sedation is a dose-limiting factor. Sodium oxybate, a salt of gamma hydroxybutyrate (GHB) FDA approved for cataplexy and narcolepsy since 2002, has been useful in alcohol-responsive movement disorders, including myoclonus-dystonia [91], and may have potential benefit in spasmodic dysphonia [34]. Side effects of somnolence, confusion, nausea, and abuse potential limit its use.

Cannabinoids have been evaluated in several neurological disorders. Improvement from cannabis use has been reported only anecdotally in cervical dystonia, blepharospasm, focal hand dystonia, and generalized dystonia [92]. An open-label prospective study in five patients of cannabidiol 200 to $600 \mathrm{mg}$ /day resulted in dose-related improvements in dystonia rating scales [93]. However, controlled studies have yielded disappointing results. In one DBRPCT of 15 dystonia patients, nabilone, a synthetic cannabinoid receptor agonist, was not effective [94], and a short controlled trial with another synthetic agent, dronabinol, was not effective in 9 patients with cervical dystonia [95].

Following reports of benefit in an open-label study in cervical dystonia, mexiletine, an oral antiarrhythmic drug derivative of lidocaine, was found to be effective in a small controlled trial of 8 patients in 2000 [96], but no further studies have been performed since. More recent developments in the pharmacologic management of dystonia include disappointing results of levetiracetam in oromandibular and cranial dystonia in a small controlled study [97]. However, zonisamide proved to be tolerable and efficacious for the motor symptoms of myoclonus-dystonia in a randomized double-blind placebo-controlled crossover trial with 24 patients [98].

Despite advances in the understanding of the pathophysiology and genetics of dystonia, there are very few ongoing clinical trials for symptomatic treatment of dystonia and none for pharmacological pathogenesis-targeted or diseasemodifying interventions. Currently ongoing or planned pharmacological trials in patients with dystonia are listed in Table 2 .

\section{Botulinum Toxin Therapy}

While blepharospasm and cervical dystonia are the only forms of dystonia for which there are FDA labels for treatment with botulinum neurotoxin (BoNT), it is commonly used off-label and considered first-line therapy in several other forms. As a general principle, BoNT injections have the benefit of being highly targeted therapies, potentially avoiding unwanted systemic effects which may be more common concerns with oral drugs. While multiple class I trials have been conducted in cervical dystonia (CD), the literature for BoNT treatment of other forms of dystonia such as oromandibular dystonia and laryngeal dystonia largely consists of open-label series and uncontrolled trials.

\section{Cervical Dystonia}

There is a high level of evidence for the efficacy of BoNT in the treatment of $\mathrm{CD}$, with class I trials demonstrating benefit in all four commercially available formulations in the USA (onabotulinumtoxinA, incobotulinumtoxinA, abobotulinumtoxin $A$, and rimabotulinumtoxinB), all of which have FDA approval for use in CD. The American Academy of Neurology (AAN) guidelines offer level A recommendation for use of abobotulinumtoxin $\mathrm{A}$ and rimabotulinumtoxinB in cervical dystonia, and level $\mathrm{B}$ recommendation for use of incobotulinumtoxin A and onabotulinumtoxinA, based on the quality of data in the literature supporting their use [99]. The 
use of electromyography (EMG) guidance of injections for cervical dystonia has been shown to result in a greater degree of clinical improvement [100], though some argue against its routine use given increased injection time, expense, and patient discomfort [101]. One pooled evaluation of adverse effects across multiple clinical trials for CD including all BoNT subtypes found weakness, dry mouth, and dysphagia to be the most commonly reported adverse effects, in 9\%, 19\%, and $14 \%$ of patients respectively. RimabotulinumtoxinB had a higher incidence of dry mouth than type A BoNT [102]. Among the different subtypes of cervical dystonia, anterocollis is regarded as a particularly challenging primary posture to treat with injections, likely related to activation of less accessible deeper muscles including the longus colli [103]. The use of auxiliary techniques to assist in safely targeting the longus colli have been described, including ultrasound or fluoroscopic guidance [104, 105]. Other deeper layer cervical muscles include the obliquus capitis inferior (OCI), which has been demonstrated to be involved in nono head tremor, and for which ultrasound-guided injection techniques have been described [106, 107]. More recent studies of BoNT in CD include a completed Phase II trial in a novel BoNT formulation, DaxibotulinumtoxinA [108] with a multicenter phase III trial currently underway (Table 2).

\section{Blepharospasm}

OnabotulinumtoxinA and incobotulinumtoxinA are FDA approved for use in blepharospasm. IncobotulinumtoxinA was initially approved for patients who had previously been treated with onabotulinumtoxinA, though the FDA label has recently been expanded to include patients without prior BoNT treatment [109]. The 2016 AAN guidelines for use of BoNT in movement disorders including blepharospasm found that no BoNT formulation had sufficient numbers of class I trials in blepharospasm to merit a level A recommendation, but offered level B recommendation for use of onabotulinumtoxin $\mathrm{A}$ and incobotulinumtoxinA, class $\mathrm{C}$ recommendation for abobotulinumtoxin $\mathrm{A}$, and insufficient evidence to rate rimabotulinumtoxinB [99]. It concluded that the three type A toxins appear to have similar efficacy. However, other reviews offer the important perspective that it is likely that few controlled studies have been performed in blepharospasm because of the robust effect size and general consensus that BoNT is considered first-line therapy for the disorder [110]. In excess of $90 \%$ of patients with blepharospasm across multiple studies experienced improvement with BoNT therapy, and the degree of benefit was often greater than $90 \%$ [110].

A general recommendation in the injection technique for blepharospasm is to avoid using the same pattern with every patient, as greater efficacy will likely be achieved with an approach that bases muscle selection and dosing on the pattern of activity observed on exam [111]. Injection of orbicularis oculi is universal given eye closure as a defining feature of blepharospasm, but the selection of the orbital or palpebral portions of the muscle may depend on patient presentation. The addition of pretarsal injections has been shown to offer additional benefit to patients with prior poor response [112]. The procerus and corrugator supercilii muscles can also be added based on apparent involvement. The use of EMG guidance is not needed for the injections of muscles involved in blepharospasm. Adverse effects may occur in 3-25\% of injections and include bruising, lagophthalmos, ptosis, entropion, and diplopia [110].

\section{Oromandibular Dystonia}

BoNT therapy is considered first-line treatment for oromandibular dystonia, though the literature primarily consists of uncontrolled observational reports including small case series. Classification of oromandibular dystonia (OMD) is typically based on the primary pattern of jaw movement, including jaw-opening, jaw-closing, and jaw-deviating forms. In aggregate, series suggest $\sim 2 / 3$ of patients receiving BoNT injections experience a moderate or greater degree of improvement $[110,113]$. One observational study evaluating 202 patients with OMD of various subtypes receiving BoNT injections over a mean period of 4.4 years found the best response in the jaw-closing cohort. It reported benefit in the injection of the submentalis complex for jaw-opening forms (including the geniohyoid, digastric, and mylohyoid), though also noted a higher complication rate, including dysphagia and dysarthria, than treatment for the jaw-closing form [113]. Muscle selection generally depends on the subtype of OMD and may include bilateral masseter, anterior temporalis, or medial pterygoids for jaw-closing subtype, contralateral lateral pterygoid or ipsilateral anterior temporalis for jaw deviation, and bilateral lateral pterygoids or digastric, platysma, mylohyoid, or geniohyoid for jaw opening [114]. Two techniques to target the lateral pterygoid muscles have been described. An external approach is through the mandibular incisura anterior to the external auditory canal and near the inferior aspect of the zygomatic arch. Alternatively, an intra-oral approach may allow more precise targeting of the muscle $[114,115]$. A recent small study of abobotulinumtoxinA in 18 patients with OMD showed improvement compared to baseline at 6 and 12 weeks in unblinded ratings, but not in blinded video assessments [116].

\section{Laryngeal Dystonia}

Laryngeal dystonia consists of dystonic activity of any of the laryngeal muscles and can present as spasmodic dysphonia (SD) in either adductor or abductor forms. More rarely, it can affect respiratory function, or present as a cough or task- 
specific singer's dystonia $[117,118]$. The first report of botulinum toxin injections to target laryngeal dystonia was in the late 1980s by Brin and Blitzer [119]. Available data are primarily from retrospective case series and open-label studies. There is only one randomized, double-blind, placebocontrolled study in adductor SD and with only 13 participants [120], though there are several additional class III trials. In the largest series of laryngeal dystonia to date including 1300 patients, $82 \%$ presented with adductor type SD and $17 \%$ with abductor SD [117]. Only 13 patients presented with adductor breathing dystonia and 5 with task-specific singer's dystonia. The results of BoNT injection in the adductor SD subgroup in this series showed an average duration of benefit of 15.1 weeks and an average benefit of $91.2 \%$ of normal function as rated by the patient. Average dose was $0.9 \mathrm{U} / 0.1 \mathrm{~mL}$ onabotulinumtoxinA per vocal fold. Side effects included $25 \%$ with breathy voice and $10 \%$ with transient cough on drinking fluids. Patients with abductor SD received injections to either unilateral or bilateral posterior cricoarytenoid muscles, with reported average best voice $70.3 \%$ of normal as rated by the patients. Average duration of benefit was 10.5 weeks. Side effects included $6 \%$ with transient dysphagia to solids and $2 \%$ with mild exertional wheezing.

A much rarer subtype of laryngeal dystonia affects respiratory function and has been labeled alternately adductor laryngeal breathing dystonia, respiratory type focal laryngeal dystonia, spasmodic laryngeal dyspnea, or respiratory laryngeal dystonia (RLD) [121]. Diagnosis typically relies on endoscopic visualization of the larynx revealing adduction of the true vocal folds during inspiration. However, laryngeal dyspnea related to dystonic activity in adjacent laryngeal regions but with normal opening of the glottis can occur [122]. Several series report improvement in RLD symptoms with botulinum toxin injections $[117,118,121]$, though no controlled studies have been performed. Injections have been described primarily in the adductor compartment, including the lateral cricothyroid and thyroarytenoid muscles, but ventricular fold injections are also reported [121]. In one series, 12 patients received onabotulinumtoxinA injections with an average dose of $0.6-3.75$ units bilaterally and experienced $55 \%$ average improvement over multiple injection sessions with a mean duration of benefit of 14 weeks [117]. In a more recent series, 11 patients received BoNT injections directed at bilateral thyroarytenoid muscles, of which 54\% experienced adequate symptom relief. Among those achieving inadequate symptom relief, however, two (18.2\%) ultimately required tracheostomy [121].

\section{Focal Hand Dystonia}

Focal hand dystonia (FHD) can be divided into task-specific (e.g. writer's cramp [WC] or musician's hand dystonia) and non task-specific forms. BoNT injection is a common treatment approach for FHD and typically the treatment of choice [123]. However, in aggregate, reported response rates to BoNT injections are lower for FHD than cervical dystonia or blepharospasm, with only approximately $50 \%$ of patients experiencing at least mild benefit in FHD as compared to about $80 \%$ in cervical dystonia or $90 \%$ in blepharospasm [124]. There are few randomized, double-blind placebo-controlled trials of BoNT therapy in FHD, with other available data coming from open-label series. Controlled trials of BoNT in FHD were primarily performed in the late 1990s to mid2000s [125-128]. Only one is considered a class I trial, in which 40 participants with WC (excluding those with marked writer's tremor) received abobotulinumtoxinA or placebo for 12 weeks in double-blind fashion [125]. The primary outcome measure was a patient report of a beneficial effect and a stated preference for continuing treatment. $70 \%$ of the treatment group met the primary outcome measure versus $31.6 \%$ of the placebo group. Adverse effects included a report of hand weakness in 18 participants receiving abobotulinumtoxinA and in 2 receiving placebo. All participants were offered abobotulinumtoxinA treatment in a 1-year follow-up extension phase of the trial; after the full year, however, only $51 \%$ remained under treatment with positive results. A class II study with double-blind crossover design included 20 patients with WC and showed improvement in speed and accuracy measurements of pen control in the treatment, but not in evaluations of writing. Patients with observable wrist deviation were found to have greater symptom benefit with BoNT injections than those without, suggesting different degrees of improvement on the basis of postural features of their presentation [126]. Another small class II double-blind crossover study included a mixed cohort of FHD, including 6 with WC, 2 with stenographer's cramp, and 2 with musician's dystonia. Objective assessments were different for each group and included a panel review of musical performances by experts, evaluations of transcription accuracy for stenographers, and evaluations of writing speed and errors for WC. Videotaped motor performances were additionally evaluated by blinded neurologists. Overall, only 4 of the 10 participants experienced improvement in subjective and objective evaluation in addition to videotaped reviews of motor performance, but a majority experienced a subjective improvement in addition to improvement in at least one other assessment category [127]. A retrospective chart review of 84 patients with musician's dystonia receiving abobotulinumtoxinA therapy included 81 with dystonia affecting the hand, of whom $47 \%$ reported at least moderate improvement by subjective report. Approximately $58 \%$ reported excessive weakness after at least one injection in the weeks leading up to the period of greatest benefit. Twenty-four continued with ongoing treatment for an average of 3 years and up to 7 years, with the forearm flexors the most frequently injected muscles [129]. Some additional 
long-term follow-up data are available in other open-label series which show only mild average benefit, but also show that many patients wished to continue receiving injections for many years suggesting that even mild benefit was clinically meaningful $[124,130]$.

In approaching BoNT injection for FHD, it is important to obtain as clear an understanding of the pattern of dystonic posturing as possible, as the correct identification of muscles to target is critical to achieve good treatment outcomes. It can be difficult in some cases to distinguish compensatory movements the patient may have adopted in order to counteract a primary dystonic posture, e.g. extending the wrist in order to realign a pen that has moved off the intended trajectory due to dystonic finger flexion. It is important to continually ask a patient's perspective on what may be compensatory and to directly examine the patient engaged in tasks that are affected by the dystonia, particularly if they have a task-specific form of FHD such as musician's dystonia. When examining a musician playing an instrument, it is important also to clarify which postures and movements are intended and customary as part of instrumental technique as opposed to unwanted dystonic movements or compensatory strategies. When injecting, the use of anatomic landmarks alone has been shown to be inaccurate in targeting muscles involved in FHD, and the use of an ancillary technique to guide injections such as EMG, ultrasound, or muscle stimulation should be employed [131].

The research experience outlined for BoNT treatment of FHD highlights difficulties in trial design, including accurately capturing treatment benefit, the need for different methods of assessments and different scales for different forms of FHD, strong placebo effect in some trials, and possibly variable response to treatment according to different underlying phenotypes. The ability to achieve adequate targeted symptom relief without causing excess weakness is of particular concern in FHD, and different injection approaches may yield highly variable degrees of success. More research is needed in appropriate muscle selection, dosing, and injection techniques. Additional well-designed controlled trials would be of value given their scarcity to date. There are several studies underway, including a placebo-controlled, double-blind, randomized crossover phase 2 trial of incobotulinumtoxinA in musician's dystonia affecting the hand, a multicenter double-blind, placebo-controlled randomized trial of incobotulinumtoxinA in FHD, and a trial comparing electrical stimulation and ultrasound to guide BoNT injections (Table 2).

\section{Lower Limb Dystonia}

While BoNT treatment of lower limb spasticity is FDA approved for onabotulinumtoxinA and abobotulinumtoxinA, no BoNT formulation has FDA indication for lower limb dystonia. There is very sparse literature in BoNT treatment of isolated lower limb dystonia, with evidence coming only from uncontrolled trials or case series. The only DBRPCT conducted in lower limb dystonia included only participants with Parkinson's disease $(n=46)$ with toe-curling dystonia, but not isolated dystonia [132]. The trial compared injections of 100 units incobotulinumtoxinA vs placebo in either flexor digitorum longus or flexor digitorum brevis muscles, with a total of two injection cycles spaced 3 months apart. The primary outcome, the average of clinical global impression (CGI) of change score 6 weeks after each of the injections, was significantly improved in the active treatment compared to the placebo group with no significant differences between the different injection sites. However, no difference was noted in the Burke-Fahn-Marsden dystonia rating scale (lower limb item) between treatment and placebo groups. An uncontrolled series documented improvement in lower limb dystonia with BoNT injection in Parkinson's disease patients who had previously undergone deep brain stimulation surgery [133]. Another uncontrolled pilot study evaluated 14 participants with lower limb dystonia affecting the foot, 10 with Parkinson's disease, and 4 with isolated dystonia. Participants received between 100 and 300 units onabotulinumtoxinA to leg and foot muscles and showed improvements in stride length, step length, and gait velocity through gait analysis, in addition to improvements on measures of pain and mobility [134]. Other case series documented improvement with BoNT injections in 6 of 8 treated patients with isolated lower limb dystonia [135] and in 6 patients with exercise-associated isolated lower limb dystonia [136].

\section{Summary}

BoNT injections are generally the treatment of choice for focal dystonia, but the evidence base is quite uneven among different forms, with robust trial data in cervical dystonia but minimal or no trial data in other forms such as lower limb dystonia. Particularly in limb dystonia, the paucity of trial data and lack of FDA indication may in some cases lead to difficulty obtaining insurance coverage for BoNT injections and create barriers in access to this therapy. Additional well-designed controlled trials would be of value to the field in clarifying treatment response, appropriate muscle selection and dosing, and injection technique.

\section{Neuromodulation}

\section{Ablations}

Stereotactic thalamotomy was first introduced as a treatment for dystonia by Irving Cooper in the 1950s, after noticing that in patients with postencephalitic parkinsonism, focal limb 
dystonia was alleviated following thalamotomies to address tremors. In a 20 -year follow-up of over 200 patients with genetic and acquired dystonia treated with basal ganglia or thalamic ablative surgeries, the majority of these patients reported significant improvement (69.7\%), including long-term symptomatic benefit [137]. In this series, younger patients of Ashkenazi Jewish descent and with a positive family history of dystonia reported the greatest improvement (85\%). Subsequent studies reported somewhat more modest results with roughly one quarter to one-half of patients seeing persistent relief [138-140], but still generally supporting Cooper's initial claim that the surgeries offered some degree of longterm efficacy.

With preliminary confidence in the stability of thalamotomies, as well as the belief that the neurological and psychological side effects of the surgery were only transient and due mainly to perilesional edema [141, 142], stereotactic thalamotomy became the preferred surgical treatment for dystonia from the mid-twentieth century through the 1990s [143]. While it was initially thought that stereotactic thalamotomies yielded stable long-term benefits, especially when treating cases of acquired dystonia [138, 140, 144], subsequent reports documented a subset of patients in whom benefits were not sustained over time [139, 140, 144].

By the 1990s, lesioning of the globus pallidus internus (GPi) had been shown to improve levodopa-induced dyskinesias and other motor features in patients with Parkinson's disease which in turn led to its use in primary generalized dystonia [145-147]. Shortly thereafter, however, these procedures were largely replaced by pallidal DBS, often preferred due to its reversibility and greater tolerability when a bilateral intervention is needed [147, 148]. DBS remains the most common neurosurgical intervention for dystonia, though stereotactic ventro-oral (VO) thalamotomies have been studied and applied clinically in Japan in recent years for focal hand dystonia, including musician's hand dystonia and writer's cramp, with unblinded series suggesting benefit $[149,150]$. Some have also argued for a continued role of ablative surgeries in other dystonia patients such as those who have a higher risk of hardware-related complications or who live far from surgical centers and may have difficulty attending frequent clinic visits for DBS programming [151].

The recent approval of magnetic resonance imagingguided high-intensity focused ultrasound (MRgFUS) for Essential Tremor has led to an interest in its possible application to other movement disorders including dystonia. This procedure creates lesions similar to those of older radiofrequency stereotactic methods but without the need for a burr hole $[152,153]$. Its use in dystonia has thus far been published in only two reports, a case series including patients with writer's cramp and brachiocervical dystonia and a case report in musician's hand dystonia, with improvement documented in both accounts $[154,155]$.

\section{Deep Brain Stimulation}

The development of stereotactic neurosurgery and the success of deep brain stimulation (DBS) in Parkinson's disease and tremor led to a revolution in the surgical treatment of dystonia. FDA approved for dystonia since 2003 under a humanitarian device exemption (HDE), DBS offers several advantages over ablation procedures, including more favorable side effect profile and adjustability, given the wide array of potential stimulation parameters.

\section{Pallidal DBS}

Posteroventral pallidal DBS is considered to be highly efficacious for severe, medication refractory, generalized, and segmental dystonias, in addition to some forms of focal dystonia [156-158]. Long-term motor symptom control and improved disability and activities of daily living have been demonstrated, with average improvements ranging from 50 to $60 \%$ depending on various factors [158-163]. However, as with DBS for Parkinson's disease and essential tremor, symptoms are often significantly improved but rarely completely absent, necessitating further improvements in the technique [164].

\section{Pallidal DBS in Generalized and Segmental Dystonia}

Several pivotal studies evaluating the effects of pallidal DBS for dystonia have demonstrated improvement in motor function, disability, and activities of daily living in isolated inherited and nongenetic dystonia. A randomized, 12-week, sham neurostimulation-controlled clinical trial with an additional 5-year follow-up period provided class I evidence for efficacy and safety of pallidal DBS in segmental and generalized dystonia $[156,160]$. This first sham-controlled DBS trial in dystonia also demonstrated a positive effect of DBS on health-related quality of life [165]. A subsequent study with blinded evaluations at 3 months [166], and a 3-year open-label extension [157], reported similar findings.

\section{Pallidal DBS in Focal Dystonia}

A randomized, sham-controlled trial of bilateral pallidal DBS on 62 patients with cervical dystonia refractory to botulinum toxin injections also provided class I evidence for this form of focal dystonia [158]. Case report and open-label evidence exists for pallidal neurostimulation in less common indications, such as Meige syndrome [167, 168] and blepharospasm [169]. 


\section{Pallidal DBS for Tardive Dystonia}

Tardive dystonia is considered to respond particularly well to pallidal DBS. In a small open-label study of 5 patients with medically refractory tardive dystonia, pallidal DBS was associated with rapid improvement in motor and functional scales [170]. Another series offered class II evidence for pallidal DBS in tardive dystonia and demonstrated its cognitive and psychiatric tolerability, with 19 patients receiving blinded evaluations at 6 months and with follow-up for up to 11 years [171]. A subsequent randomized sham neurostimulation trial did not meet its primary end point at 3 months, attributed to incomplete recruitment. However, improvements in secondary endpoints did provide additional evidence for efficacy and safety [172].

\section{Variability in Pallidal DBS Outcomes}

Despite favorable outcomes, there is wide variability in reported DBS outcomes, and nonresponders are not uncommon [156] even in experienced surgical centers [143]. This variability is, in part, dependent on patient selection and dystonia etiology, among both isolated and combined dystonia [173]. For example, while favorable outcomes are anticipated for dystonia caused by the GAG deletion in TOR $1 A$ and in myoclonus-dystonia, outcomes in THAP1 pathogenic variants are less predictable, and DBS is not helpful in ATP1A3 defects (RDP) [161, 174]. Location and extent of volume of tissue activated (VTA) are additional predictive factors of therapeutic efficacy in pallidal DBS [175]. Clinical characteristics that predict more favorable outcomes include mobile dystonia (as opposed to fixed postures associated with underlying contractures); short disease duration; younger age at surgery; lack of significant medical, cognitive, and psychiatric comorbidities; and absence of concomitant spasticity or ataxia [163, 173]. Generally, speech and swallowing impairments improve to a lesser extent than dystonia affecting limb and axial symptoms [163].

\section{DBS of Nonpallidal Targets}

While less studied in dystonia, stimulation of brain targets other than the globus pallidus has also been shown to lead to improvement in dystonia. Subthalamic stimulation is the best documented, and class IV evidence supports its tolerability and sustained efficacy in cervical, segmental, and generalized isolated dystonia $[176,177]$. Targeting the thalamic ventralis intermedius nucleus (Vim) is now considered to be an equivalent, or even superior, approach to targeting the globus pallidus for the management of dystonic tremor, as well as for cases where tremor is the patient's most disabling symptom $[178,179]$.

\section{DBS for Acquired and Heredodenegerative Dystonia}

Surgical treatments of acquired and heredodegenerative forms of dystonia are perceived to be less effective in general than of isolated dystonia [180]. Response rates of pallidal stimulation in acquired dystonia are generally modest and unpredictable, with a mean reduction of dystonia symptoms of only $\sim 23 \%$ and with frequent nonresponder cases [181]. Greater improvement is seen among younger individuals and those with anatomical integrity of the basal ganglia on preoperative imaging [180]. Growing recognition that brain structures outside the basal ganglia are involved in dystonia pathogenesis as well has prompted preliminary evaluations of alternative targets including the thalamic ventralis oralis posterior (Vop) and Vim [182-184] nuclei, and deep cerebellar nuclei [185].

\section{DBS Safety Profile and Recent Advances}

Surgery-related risks and complications of DBS include intracerebral hemorrhage (1-2\%, including clinically asymptomatic hemorrhages), seizure (1\%), and other rare surgical complications such as deep venous thrombosis, pulmonary embolism, pneumonia, and urinary tract infections [164, 186, 187]. Risks inherently related to the DBS device include device-related infections, lead migration, and lead fracture, all of which are more prevalent in younger patients with dystonia [72]. One large long-term followup series of patients with dystonia related to TOR $1 A$ defects reported an $8.5 \%$ incidence of delayed infections or hardware complications requiring reoperation, and a $4.3 \%$ rate of reoperations to reposition leads [188]. Stimulation side effects, ranging from motor and sensory symptoms to psychiatric and autonomic effects, are reversible, highly variable, and depend on the target and exact location of the electrodes. In patients with dystonia, speech abnormalities related to capsular spread are the most commonly reported stimulation side effect [163]. Bradykinesia, akinesia, and freezing of gait also have been reported with bilateral pallidal stimulation [163, 168, 189, 190].

Advances in stereotactic neurosurgery have allowed for more precise targeting with higher-resolution imaging, and the ability to implant intracranial electrodes via MRguidance under general anesthesia [191]. Recent advances in DBS include the advent of new devices with additional programming capabilities, including newer rechargeable implantable pulse generators (IPGs), and directional leads allowing current steering which may reduce side effects related to unwanted stimulation of neighboring areas [192]. There is also considerable recent interest in closedloop (adaptive) DBS paradigms, in which stimulation is increased or decreased based on neurophysiological biomarkers detected from the DBS lead. While its use is still 
quite preliminary in dystonia, several studies have identified features of pallidal low-frequency oscillations which may serve as potential biomarkers for closed-loop stimulation [193-195].

\section{Noninvasive Neuromodulation}

There has long been an interest in designing protocols of noninvasive stimulation such as transcranial direct current stimulation (tDCS) or transcranial magnetic stimulation (TMS) for therapeutic benefit for patients with dystonia, particularly for those who have experienced inadequate benefit from BoNT injection or are poor candidates for deep brain stimulation. To date, success has been limited in demonstrating enduring benefits from these approaches, but several studies have pointed to shorter-term benefits or physiological changes that may suggest potential for positive impact on dystonia and merit additional study. In the context of dystonia, noninvasive stimulation has been evaluated primarily in FHD and CD.

\section{Transcranial Magnetic Stimulation}

\section{Focal Hand Dystonia}

An early open-label study of repetitive TMS (rTMS) targeting primary motor cortex (M1) in $16 \mathrm{WC}$ patients resulted in reduced writing pressure and subjective benefit for up to $3 \mathrm{~h}$ [196], though a later single-blinded, sham-controlled trial in 9 patients with WC showed improved handwriting and pen pressure with the premotor cortex (PMC) but not M1 stimulation [197]. PMC stimulation has been evaluated in several other studies with variable results. Benefit was seen also in a partial crossover trial with sham-stimulation control in 3 patients with WC and 3 with musician's FHD in which improvement in handwriting was seen after multiple, but not single, TMS sessions targeting PMC [198]. Another study evaluated continuous theta burst stimulation (cTBS) to dorsal PMC, resulting in improved writing speed in $15 \mathrm{WC}$ patients, but no changes in markers of surround inhibition; however, this trial had no sham-stimulation comparator, so clinical improvements must be interpreted with caution [199]. Other studies, however, have demonstrated no clinically meaningful benefit with rTMS to the PMC in mixed cohorts of WC and FHD $[200,201]$. Other studies in WC include one showing benefit to writing on objective and subjective evaluations in a doubleblinded crossover trial of $11 \mathrm{WC}$ patients with five sessions of stimulation to primary sensory cortex (S1) [202] and one showing no measurable benefit with a single session of cerebellar theta burst stimulation in a cohort of 10 patients with WC [203].

\section{Cervical Dystonia}

Several studies have evaluated TMS in CD. A protocol of 2 weeks of cerebellar theta burst TMS showed benefit in a randomized sham-stimulation controlled trial of 20 patients with $\mathrm{CD}$, with those in the treatment group showing clinical improvement as measured by the TWSTRS scale, though benefit was not seen at 2- or 4-week follow-up [204]. Another small study with $8 \mathrm{CD}$ patients examined rTMS over several cortical sites and found no significant improvement in TWSTRS scores, but saw nonsignificant improvement that was greatest over dPMC and M1 [205]. An open-label study of $12 \mathrm{CD}$ patients showed no clinical effect with two 20-min sessions of stimulation to M1 and S1 [206].

\section{Other Dystonia}

There have been few investigations of TMS in other forms of dystonia, though a randomized, sham-controlled trial evaluating rTMS to the ACC in 12 patients with blepharospasm showed objective clinical improvement by blinded video review up to $1 \mathrm{~h}$ after stimulation [207]. An evaluation of 10 sessions of rTMS to M1 in a single patient with focal leg dystonia showed no clinical benefit [208].

\section{Transcranial Direct Current Stimulation and Transcranial Alternating Current Stimulation}

\section{Focal Hand Dystonia and Cervical Dystonia}

A number of studies have investigated the use of either cathodal or anodal tDCS in FHD, including WC or musician's FHD. Many of these showed no clinical benefit [209-212], though one double-blinded, sham-controlled trial in 30 musician's FHD patients showed greater improvement with biparietal tDCS in conjunction with a rehabilitative program ("sensory motor retuning" therapy) as compared to the rehabilitative program alone [213]. Another blinded shamcontrolled study in 10 pianists with FHD showed improvement in rhythmic accuracy of a repetitive musical passage after simultaneous cathodal tDCS to M1 contralateral to the affected hand and anodal tDCS to M1 contralateral to the unaffected hand, though only in conjunction with a motor learning task [214]. Isolated evaluations of single patients have suggested some improvement in CD with anodal tDCS to the cerebellum [215] and $15-\mathrm{Hz}$ transcranial alternating current stimulation (tACS) to the sensorimotor cortex [216].

\section{Other Noninvasive Stimulation}

In a different noninvasive stimulation modality, a small openlabel study examined the effects of laryngeal vibrotactile stimulation (VTS) in 13 participants with adductor SD, showing 
that vibratory stimuli delivered to the laryngeal area lateral to the thyroid cartilage were associated with either a reduction in the number of voice breaks or improvement in acoustic signal measures of smoothness of speech in $69 \%$ [217]. The application of VTS was associated with suppression of lowfrequency oscillations over somatosensory and premotor cortex on EEG.

In summary, there is not sufficient evidence to recommend noninvasive stimulation techniques in the clinical care of dystonia at this time, though several studies suggest PMC as a potential target in FHD and a limited amount of data suggest possible benefit with cerebellar stimulation in $\mathrm{CD}$. The use of noninvasive stimulation in combination with rehabilitation interventions is also a compelling concept with some preliminary evidence to support further investigation in welldesigned trials.

\section{Rehabilitation Interventions}

The literature in rehabilitative approaches for dystonia is marked by significant heterogeneity of intervention techniques, making it somewhat difficult to pool results and generalize findings. Their study is additionally difficult due to the challenge in designing truly blinded control conditions as comparators. In a recent systematic review of rehabilitative interventions in dystonia, Prudente and colleagues offered an approach whereby studies were pooled and evaluated together on the basis of their primary premise or theoretical basis, even if precise interventions varied [218]. They grouped studies into six categories: "movement practice," in which intensive motor training is the central intervention; "training with constraint," in which compensatory movements in unaffected joints are limited by some form of physical restraining; "sensory reorganization," in which efforts are undertaken in order to reorganize a deranged cortical sensory map; "normalization of muscle activity with external techniques," in which passive or active external methods are applied to normalize affected muscle activity, such as biofeedback or kinesiotaping strategies; "neuromodulation with training," in which a variety of neuromodulation approaches in combination with motor practice aim to modify brain excitability to improve voluntary control; and "compensatory strategies," in which a modified movement approach is introduced to compensate for or replace an abnormal motor program. This offers a helpful framework by which to categorize individual studies. Utilizing the GRADE approach [219], they classified the quality of evidence for each category of intervention as represented in the 45 included studies within 4 tiers of GRADE quality ratings (very low, low, moderate, or high). They concluded that evidence for interventions in all categories was "very low," with the exception of the movement practice and the neuromodulation with training categories which were each rated as having a "low" level of evidence. Some authors have suggested that, given the rarity and phenotypic variability in dystonia, the gold standard of randomized placebo-controlled trials may not be practical in evaluating rehabilitation interventions for the condition, and that other study designs using carefully designed small $n$ methodology be considered [220].

\section{Focal Hand Dystonia}

Several different rehabilitative approaches have been described in upper limb dystonia. There was previously interest in constraint-based therapy in occupational hand dystonia in which the affected forearm and hand were immobilized with a splint for an extended period of time [221]. However, this approach has largely fallen out of favor [220]. An alternative method of constraint-based intervention involves constraining only the unaffected joints in a hand in order to minimize the occurrence of compensatory movements, typically in conjunction with a motor training program using the dystonic fingers. This general approach has been variably labeled constraintinduced therapy (CIT), constraint-induced movement therapy, and sensory motor retuning (SMR) [222-224]. It has been studied in WC with mild objective benefit on handwriting after 4 weeks [225]. It has been studied also in musicians with FHD in several uncontrolled studies [222-224, 226, 227] all reporting improvement, though one study showed benefit that varied by instrument type (improvement in 6 pianists and 2 guitarists, but not in 3 wind instrumentalists) [222]. Another intervention termed "slow-down therapy" showed benefit in an uncontrolled study of 20 pianists with FHD [228]. In this method, musical passages were practiced at slow enough a tempo for dystonic movements to disappear, with very gradual tempo increases over time.

A third type of intervention incorporates a sensory retraining paradigm as a major component, given the deranged boundaries of cortical sensory fields that have been demonstrated in FHD and the hypothesis that abnormal sensorimotor integration plays a key role in its pathophysiology [229, 230]. In a study of one such intervention, participants with FHD learned braille reading and showed improvement in measures of sensory discrimination and dystonia after 8 weeks [231]. Three participants showed further gains after 1 year of continued sensory training [232].

Other approaches have combined sensory training with various motor training protocols. In one study in 11 patients with FHD, participants received a variety of sensory training interventions, including reading Braille, identifying shapes, numbers, or letters drawn onto the hand, and feeling objects shielded from the field of view and matching the shape with pictures. They also performed other visualization exercises, underwent a biofeedback intervention, and performed motor training exercises focused on normalizing patterns of movements, strengthening hand intrinsic muscles, and improving 
ergonomics of movement. Following the protocol, participants showed improvements in several sensory measures in addition to measures of motor control and accuracy [233]. In a later study, the same authors labeled the approach "learningbased sensorimotor training (LBSMT)," and designed another protocol of its use in 13 FHD patients in conjunction with a home-based fitness program, dietary recommendations, and a computer-based program purportedly targeting learning and memory [230]. After an 8-week program, participants showed improvements in measures of sensory discrimination and taskspecific performance. Other authors have pointed out the difficulty, however, in interpreting results from studies with such complex and varied protocols and in isolating which interventions were helpful [225].

Bleton and colleagues compared finger representation in the $\mathrm{S} 1$ cortex in $11 \mathrm{WC}$ patients who had experienced substantial improvement in a rehabilitative program to that of $10 \mathrm{WC}$ patients who had not undergone the program and 11 healthy controls [234]. The rehabilitative program occurred over several months and consisted of relaxation and other motor training techniques. The WC cohort that had benefited from the rehabilitation program showed hand representation in the S1 cortex with even more clean demarcations of each finger than healthy controls, whereas the untreated WC patients showed disorganized finger somatotopy. While compelling, the lack of randomization limits generalizability of these results as the treated cohort whose cortical somatotopy was evaluated was specifically selected due to its participants' significant improvement with rehabilitation and whose benefit and pattern of cortical representation may therefore have related to factors other than the intervention itself.

The authors of a recent systematic review [235] of different rehabilitative interventions for musicians with FHD identified 9 studies reaching their defined inclusion criteria including studies of CIT [224, 236], LBSMT [237], SMR $[222,226,227]$, and slow-down therapy [228, 238]. They concluded that there was moderate evidence to support their use in musicians with FHD but with caveats regarding lack of reliability or validity testing in many of the outcome measures in the studies. All but one of the included studies were Level III or IV evidence, and none was Level I.

\section{Cervical Dystonia}

A variety of rehabilitative interventions have been studied in $\mathrm{CD}$, including in several randomized controlled trials (RCTs). One randomized 12 participants to either EMG biofeedback to try to improve sternocleidomastoid muscle overactivity or a program of progressive muscle relaxation without the use of EMG biofeedback. Both groups showed reduced neck muscle activity, but greater reduction was seen in the EMG biofeedback group [239]. In contrast, another
RCT randomized 11 patients to either visual video feedback of head position or visual video feedback plus EMG biofeedback and failed to show any improvement in objective indices of excessive neck activity or head movement in either group [240]. However, nearly all participants described subjective improvement. Another RCT compared a 12-week program of active neck exercises plus relaxation compared to a whole-body relaxation program alone in a cohort of 20 participants [241]. The active neck exercises were designed individually per participant to activate and strengthen muscles of the neck that were in opposition to their dystonic neck posture. There were no significant differences between groups in the primary outcome of the Toronto Western Spasmodic Torticollis Rating Scale (TWSTRS), though there was a trend toward improvement in the exercise group that the study may have been underpowered to detect as significant. Other studies have examined the combination of BoNT injections and physiotherapy, including a crossover study with 40 participants randomized to BoNT injections plus a specific program of physiotherapy or BoNT injections alone [242]. The BoNT plus physiotherapy intervention was associated with a longer duration of clinical benefit after injection and required a lower dose at reinjection, in addition to greater reductions in measures of disability in activities of daily living and subjective pain. Another RCT, also with 40 participants, tested BoNT injections combined with a physiotherapy program of stretching, training of voluntary movements, and transcutaneous electrical nerve stimulation (TENS) [243]. The control group received BoNT injections combined with a placebo TENS protocol. Those in the BoNT plus physiotherapy group showed greater improvement in measures of rotational head deviation and in disability scores. A more recent trial randomized 26 participants to BoNT plus physiotherapy or BoNT alone, with greater improvement in TWSTRS score in the PT-BoNT than in the control arm [244]. A third, smaller trial, evaluated BoNT injections combined with physiotherapy and functional electrical stimulation of muscles that were antagonistic to the primary dystonic posture as compared to BoNT injection alone [245]. Cohort assignment was not randomized, but instead based on patients' availability to attend PT sessions. The PT plus BoNT cohort showed improvements in severity and disability subscales on TWSTRS as compared to improvement only in the severity subscale in the control group. Additionally, the PT plus BoNT cohort showed greater improvement in measures of pain and quality of life. The lack of randomization, however, does limit interpretation of these results given potential selection bias. A longer-term study randomized $72 \mathrm{CD}$ patients who were stable on BoNT treatment to either routine or specialized physiotherapy protocols and followed them for 12 months [246]. The specialized physiotherapy protocol aimed to strengthen muscles antagonistic to the main dystonic posture and to improve motor 
skills with structured feedback. There were no differences between groups at 12 months in the primary outcome, TWSTRS scale, though both groups improved on the TWSTRS disability scale compared to baseline. The specialized physiotherapy group did show a greater degree of selfperceived improvement and also higher scores on a measure of general health perception.

\section{Conclusions}

While progress has been made in recent years in the understanding and treatment of dystonia, there is a critical need for further advances. Botulinum toxin injections and deep brain stimulation have revolutionized the treatment of dystonia, but symptom relief may be incomplete and benefit is not universal to all forms of dystonia. Comprehensive treatment may ultimately rely on multiple different approaches, with variable combinations of pharmacotherapy, botulinum toxin injections, rehabilitation, and neuromodulation, rather than relying on one modality alone. With further understanding of the underlying pathophysiology of dystonia, there hopefully will be increasingly sophisticated treatments directed at the underlying abnormalities, moving the field closer to true diseasemodifying therapies.

Required Author Forms Disclosure forms provided by the authors are available with the online version of this article.

\section{References}

1. Bell SA, Tudur Smith C. A comparison of interventional clinical trials in rare versus non-rare diseases: an analysis of ClinicalTrials.gov. Orphanet J Rare Dis. 2014;9:170.

2. Jinnah HA, Albanese A, Bhatia KP, Cardoso F, Da Prat G, de Koning TJ, et al. Treatable inherited rare movement disorders. Mov Disord. 2018;33(1):21-35.

3. Anagianni S, Tuschl K. Genetic Disorders of Manganese Metabolism. Curr Neurol Neurosci Rep. 2019;19(6):33.

4. Bandmann O, Weiss KH, Kaler SG. Wilson's disease and other neurological copper disorders. Lancet Neurol. 2015;14(1):103-13.

5. Mochel F, Hainque E, Gras D, Adanyeguh IM, Caillet S, Héron B, et al. Triheptanoin dramatically reduces paroxysmal motor disorder in patients with GLUT1 deficiency. Journal of neurology, neurosurgery, and psychiatry. 2016;87(5):550-3.

6. Leen WG, Mewasingh L, Verbeek MM, Kamsteeg EJ, van de Warrenburg BP, Willemsen MA. Movement disorders in GLUT1 deficiency syndrome respond to the modified Atkins diet. Mov Disord. 2013;28(10):1439-42.

7. Kölker S, Christensen E, Leonard JV, Greenberg CR, Boneh A, Burlina AB, et al. Diagnosis and management of glutaric aciduria type I-revised recommendations. J Inherit Metab Dis. 2011;34(3): $677-94$.
8. Morris AA, Kozich V, Santra S, Andria G, Ben-Omran TI, Chakrapani AB, et al. Guidelines for the diagnosis and management of cystathionine beta-synthase deficiency. J Inherit Metab Dis. 2017;40(1):49-74.

9. Baumgartner MR, Horster F, Dionisi-Vici C, Haliloglu G, Karall $\mathrm{D}$, Chapman KA, et al. Proposed guidelines for the diagnosis and management of methylmalonic and propionic acidemia. Orphanet J Rare Dis. 2014;9:130.

10. Latorre A, Bhatia KP. Treatment of Paroxysmal Dyskinesia. Neurol Clin. 2020;38(2):433-47.

11. Tabarki B, Alfadhel M, AlShahwan S, Hundallah K, AlShafi S, AlHashem A. Treatment of biotin-responsive basal ganglia disease: Open comparative study between the combination of biotin plus thiamine versus thiamine alone. Eur J Paediatr Neurol. 2015;19(5):547-52.

12. Wassenberg T, Molero-Luis M, Jeltsch K, Hoffmann GF, Assmann B, Blau N, et al. Consensus guideline for the diagnosis and treatment of aromatic 1-amino acid decarboxylase (AADC) deficiency. Orphanet J Rare Dis. 2017;12(1):12.

13. Wijemanne S, Jankovic J. Dopa-responsive dystonia-clinical and genetic heterogeneity. Nature Reviews Neurology. 2015;11(7):414-24.

14. Willemsen MA, Verbeek MM, Kamsteeg E-J, de Rijk-van Andel JF, Aeby A, Blau N, et al. Tyrosine hydroxylase deficiency: a treatable disorder of brain catecholamine biosynthesis. Brain. 2010;133(6):1810-22.

15. Almannai M, Felemban R, Saleh MA, Faqeih EA, Alasmari A, AlHashem A, et al. 6-Pyruvoyltetrahydropterin Synthase Deficiency: Review and Report of 28 Arab Subjects. Pediatr Neurol. 2019;96:40-7.

16. Friedman J, Roze E, Abdenur JE, Chang R, Gasperini S, Saletti V, et al. Sepiapterin reductase deficiency: a treatable mimic of cerebral palsy. Ann Neurol. 2012;71(4):520-30.

17. Longo N. Disorders of biopterin metabolism. J Inherit Metab Dis. 2009;32(3):333-42.

18. Thöny B, Blau N. Mutations in the BH4-metabolizing genes GTP cyclohydrolase I, 6-pyruvoyl-tetrahydropterin synthase, sepiapterin reductase, carbinolamine-4a-dehydratase, and dihydropteridine reductase. Human Mutation. 2006;27(9):870-8.

19. Nygaard TG, Marsden CD, Fahn S. Dopa-responsive dystonia: long-term treatment response and prognosis. Neurology. 1991;41(2 ( Pt 1)):174-81.

20. Ichinose H, Ohye T, Takahashi E, Seki N, Hori T, Segawa M, et al. Hereditary progressive dystonia with marked diurnal fluctuation caused by mutations in the GTP cyclohydrolase I gene. Nat Genet. 1994;8(3):236-42.

21. Segawa M, Hosaka A, Miyagawa F, Nomura Y, Imai H. Hereditary progressive dystonia with marked diurnal fluctuation. Adv Neurol. 1976;14:215-33.

22. Neville BGR, Parascandalo R, Farrugia R, Felice A. Sepiapterin reductase deficiency: a congenital dopa-responsive motor and cognitive disorder. Brain. 2005;128(10):2291-6.

23. Bonafe L, Thony B, Penzien JM, Czarnecki B, Blau N. Mutations in the sepiapterin reductase gene cause a novel tetrahydrobiopterin-dependent monoamine-neurotransmitter deficiency without hyperphenylalaninemia. Am J Hum Genet. 2001;69(2):269-77.

24. Hanihara T, Inoue K, Kawanishi C, Sugiyama N, Miyakawa T, Onishi $\mathrm{H}$, et al. 6-Pyruvoyl-tetrahydropterin synthase deficiency with generalized dystonia and diurnal fluctuation of symptoms: a clinical and molecular study. Mov Disord. 1997;12(3):408-11.

25. Brüggemann N, Spiegler J, Hellenbroich Y, Opladen T, Schneider SA, Stephani U, et al. Beneficial Prenatal Levodopa Therapy in Autosomal Recessive Guanosine Triphosphate Cyclohydrolase 1 Deficiency. Archives of Neurology. 2012;69(8):1071-5. 
26. Kim R, Jeon B, Lee W-W. A Systematic Review of Treatment Outcome in Patients with Dopa-responsive Dystonia (DRD) and DRD-Plus. Movement Disorders Clinical Practice. 2016;3(5): 435-42.

27. Tadic V, Kasten M, Bruggemann N, Stiller S, Hagenah J, Klein C. Dopa-responsive dystonia revisited: diagnostic delay, residual signs, and nonmotor signs. Arch Neurol. 2012;69(12):1558-62.

28. Trender-Gerhard I, Sweeney MG, Schwingenschuh P, Mir P, Edwards MJ, Gerhard A, et al. Autosomal-dominant GTPCH1deficient DRD: clinical characteristics and long-term outcome of 34 patients. Journal of Neurology, Neurosurgery \&amp; Psychiatry. 2009;80(8):839-45.

29. Dong W, Luo B, Qiu C, Jiang X, Qu X, Zhang L, et al. Deep Brain Stimulation for the Treatment of Dopa-Responsive Dystonia: A Case Report and Literature Review. World Neurosurg. 2020;136: 394-8.e5.

30. Pons R, Syrengelas D, Youroukos S, Orfanou I, Dinopoulos A, Cormand B, et al. Levodopa-induced dyskinesias in tyrosine hydroxylase deficiency. Mov Disord. 2013;28(8):1058-63.

31. Chien YH, Lee NC, Tseng SH, Tai CH, Conway AM, Pykett M, et al. AGIL-AADC gene therapy results in sustained improvements in motor and developmental milestones through 5 years in children with AADC deficiency. Journal of the Neurological Sciences. 2019;405:27.

32. Bull PC, Thomas GR, Rommens JM, Forbes JR, Cox DW. The Wilson disease gene is a putative copper transporting P-type ATPase similar to the Menkes gene. Nature Genetics. 1993;5(4): 327-37.

33. Weiss KH, Thurik F, Gotthardt DN, Schafer M, Teufel U, Wiegand F, et al. Efficacy and safety of oral chelators in treatment of patients with Wilson disease. Clin Gastroenterol Hepatol. 2013;11(8):1028-35.e1-2.

34. Termsarasab P, Thammongkolchai T, Frucht SJ. Medical treatment of dystonia. J Clin Mov Disord. 2016;3:19.

35. Jankovic J. Medical treatment of dystonia. Movement Disorders. 2013;28(7):1001-12.

36. Clark LN, Wang Y, Karlins E, Saito L, Mejia-Santana H, Harris J, et al. Frequency of LRRK2 mutations in early- and late-onset Parkinson disease. Neurology. 2006;67(10):1786-91.

37. Bernard G, Vanasse M, Chouinard S. A case of secondary dystonia responding to levodopa. J Child Neurol. 2010;25(6):780-1.

38. Kitahara M, Shimohata T, Tokunaga J, Nishizawa M. Cervical dystonia associated with spinocerebellar ataxia type 2 successfully treated with levodopa: a case report. Mov Disord. 2009;24(14): 2163-4.

39. Peall KJ, Kurian MA, Wardle M, Waite AJ, Hedderly T, Lin J-P, et al. SGCE and myoclonus dystonia: motor characteristics, diagnostic criteria and clinical predictors of genotype. J Neurol. 2014;261(12):2296-304.

40. Luciano MS, Ozelius L, Sims K, Raymond D, Liu L, SaundersPullman R. Responsiveness to levodopa in epsilon-sarcoglycan deletions. Movement Disorders. 2009;24(3):425-8.

41. Nardocci N, Zorzi G, Barzaghi C, Zibordi F, Ciano C, Ghezzi D, et al. Myoclonus-dystonia syndrome: clinical presentation, disease course, and genetic features in 11 families. Mov Disord. 2008;23(1):28-34.

42. Rughani AI, Lozano AM. Surgical treatment of myoclonus dystonia syndrome. Mov Disord. 2013;28(3):282-7.

43. Heinzen EL, Arzimanoglou A, Brashear A, Clapcote SJ, Gurrieri F, Goldstein DB, et al. Distinct neurological disorders with ATP1A3 mutations. The Lancet Neurology. 2014;13(5):503-14.

44. Zúñiga-Ramírez C, Kramis-Hollands M, Mercado-Pimentel R, González-Usigli HA, Sáenz-Farret M, Soto-Escageda A, et al. Generalized Dystonia and Paroxysmal Dystonic Attacks due to a Novel ATP1A3 Variant. Tremor Other Hyperkinet Mov (N Y). 2019;9:https://doi.org/10.7916/tohm.v0.723.
45. Termsarasab P, Yang AC, Frucht SJ. Intermediate Phenotypes of ATP1A3 Mutations: Phenotype-Genotype Correlations. Tremor Other Hyperkinet Mov (N Y). 2015;5:336

46. Lang AE. Dopamine agonists and antagonists in the treatment of idiopathic dystonia. Adv Neurol. 1988;50:561.

47. Fan X, Donsante Y, Jinnah HA, Hess EJ. Dopamine Receptor Agonist Treatment of Idiopathic Dystonia: A Reappraisal in Humans and Mice. J Pharmacol Exp Ther. 2018;365(1):20-6.

48. Marsden CD, Marion MH, Quinn N. The treatment of severe dystonia in children and adults. J Neurol Neurosurg Psychiatry. 1984;47(11):1166-73.

49. Pinninti NR, Faden J, Adityanjee A. Are Second-Generation Antipsychotics Useful in Tardive Dystonia? CLINICAL NEUROPHARMACOLOGY. 2015;38(5):183-97.

50. Girotti F, Scigliano G, Nardocci N, Angelini L, Broggi G, Giovannini P, et al. Idiopathic dystonia: neuropharmacological study. J Neurol. 1982;227(4):239-47.

51. Giménez-Roldán S, Mateo D, Orbe M, Muñoz-Blanco JL, Hípola D. Acute pharmacologic tests in cranial dystonia. Adv Neurol. 1988;49:451.

52. Jinnah HA, Factor SA. Diagnosis and treatment of dystonia Neurologic clinics. 2015;33(1):77-100.

53. Aguilar L, Lorenzo C, Fernández-Ovejero R, Roncero C, Montejo AL. Tardive Dyskinesia After Aripiprazole Treatment That Improved With Tetrabenazine, Clozapine, and Botulinum Toxin. Front Pharmacol. 2019;10:281.

54. Jankovic J. Treatment of hyperkinetic movement disorders with tetrabenazine: A double-blind crossover study. Annals of Neurology. 1982;11(1):41-7.

55. Chen JJ, Ondo WG, Dashtipour K, Swope DM. Tetrabenazine for the treatment of hyperkinetic movement disorders: a review of the literature. Clin Ther. 2012;34(7):1487-504.

56. Leung JG, Breden EL. Tetrabenazine for the Treatment of Tardive Dyskinesia. Annals of Pharmacotherapy. 2011;45(4):525-31.

57. Jankovic J. Dopamine depleters in the treatment of hyperkinetic movement disorders. Expert Opinion on Pharmacotherapy. 2016;17(18):2461-70.

58. Fernandez HH, Factor SA, Hauser RA, Jimenez-Shahed J, Ondo WG, Jarskog LF, et al. Randomized controlled trial of deutetrabenazine for tardive dyskinesia: The ARM-TD study. Neurology. 2017;88(21):2003-10.

59. Anderson KE, Stamler D, Davis MD, Factor SA, Hauser RA, Isojärvi $\mathrm{J}$, et al. Deutetrabenazine for treatment of involuntary movements in patients with tardive dyskinesia (AIM-TD): a double-blind, randomised, placebo-controlled, phase 3 trial. Lancet Psychiatry. 2017;4(8):595-604.

60. Fernandez HH, Stamler D, Davis MD, Factor SA, Hauser RA, Jimenez-Shahed J, et al. Long-term safety and efficacy of deutetrabenazine for the treatment of tardive dyskinesia. Journal of neurology, neurosurgery, and psychiatry. 2019;90(12):131723 .

61. Hauser RA, Factor SA, Marder SR, Knesevich MA, Ramirez PM, Jimenez R, et al. KINECT 3: A Phase 3 Randomized, DoubleBlind, Placebo-Controlled Trial of Valbenazine for Tardive Dyskinesia. Am J Psychiatry. 2017;174(5):476-84.

62. Kane JM, Correll CU, Liang GS, Burke J, O'Brien CF. Efficacy of Valbenazine (NBI-98854) in Treating Subjects with Tardive Dyskinesia and Schizophrenia or Schizoaffective Disorder. Psychopharmacology bulletin. 2017;47(3):69-76.

63. Correll CU, Josiassen RC, Liang GS, Burke J, O'Brien CF. Efficacy of Valbenazine (NBI-98854) in Treating Subjects with Tardive Dyskinesia and Mood Disorder. Psychopharmacol Bull. 2017;47(3):53-60

64. O'Brien CF, Jimenez R, Hauser RA, Factor SA, Burke J, Mandri $\mathrm{D}$, et al. NBI-98854, a selective monoamine transport inhibitor for 
the treatment of tardive dyskinesia: A randomized, double-blind, placebo-controlled study. Mov Disord. 2015;30(12):1681-7.

65. Josiassen RC, Kane JM, Liang GS, Burke J, O'Brien CF. LongTerm Safety and Tolerability of Valbenazine (NBI-98854) in Subjects with Tardive Dyskinesia and a Diagnosis of Schizophrenia or Mood Disorder. Psychopharmacol Bull. 2017;47(3):61-8.

66. Solmi M, Pigato G, Kane JM, Correll CU. Treatment of tardive dyskinesia with VMAT-2 inhibitors: a systematic review and meta-analysis of randomized controlled trials. Drug Des Devel Ther. 2018;12:1215-38.

67. Truong DD, Sandroni P, van den Noort S, Matsumoto RR. Diphenhydramine is effective in the treatment of idiopathic dystonia. Arch Neurol. 1995;52(4):405-7.

68. Pisani A, Bernardi G, Ding J, Surmeier DJ. Re-emergence of striatal cholinergic interneurons in movement disorders. Trends Neurosci. 2007;30(10):545-53.

69. Deffains M, Bergman H. Striatal cholinergic interneurons and cortico-striatal synaptic plasticity in health and disease. Mov Disord. 2015;30(8):1014-25.

70. Corner BD. Dystonia musculorum deformans in siblings; treated with artane (trihexyphenidyl). Proc R Soc Med. 1952;45(7):451-2.

71. Burke RE, Fahn S, Marsden CD. Torsion dystonia: a doubleblind, prospective trial of high-dosage trihexyphenidyl. Neurology. 1986;36(2):160-4.

72. Air EL, Ostrem JL, Sanger TD, Starr PA. Deep brain stimulation in children: experience and technical pearls. Journal of neurosurgery Pediatrics. 2011;8(6):566-74

73. Fahn S. High dosage anticholinergic therapy in dystonia. Neurology. 1983;33(10):1255-61.

74. Garibotto V, Romito LM, Elia AE, Soliveri P, Panzacchi A, Carpinelli A, et al. In vivo evidence for GABA(A) receptor changes in the sensorimotor system in primary dystonia. Mov Disord. 2011;26(5):852-7.

75. Greene P, Shale H, Fahn S. Analysis of open-label trials in torsion dystonia using high dosages of anticholinergics and other drugs. Mov Disord. 1988;3(1):46-60.

76. Greene PE, Fahn S. Baclofen in the treatment of idiopathic dystonia in children. Mov Disord. 1992;7(1):48-52.

77. Rosse RB, Allen A, Lux WE. Baclofen treatment in a patient with tardive dystonia. J Clin Psychiatry. 1986;47(9):474-5.

78. Brennan MJ, Ruff P, Sandyk R. Efficacy of a combination of sodium valproate and baclofen in Meige's disease (idiopathic orofacial dystonia). Br Med J (Clin Res Ed). 1982;285(6345):853.

79. Narayan RK, Loubser PG, Jankovic J, Donovan WH, Bontke CF. Intrathecal baclofen for intractable axial dystonia. Neurology. 1991;41(7):1141-2.

80. Butler C, Campbell S. Evidence of the effects of intrathecal baclofen for spastic and dystonic cerebral palsy. Developmental Medicine \& Child Neurology. 2000;42(9):634-45.

81. Walker RH, Danisi FO, Swope DM, Goodman RR, Germano IM, Brin MF. Intrathecal baclofen for dystonia: Benefits and complications during six years of experience. Movement Disorders. 2000;15(6):1242-7.

82. Hou JGG, Ondo W, Jankovic J. Intrathecal baclofen for dystonia. Movement Disorders. 2001;16(6):1201-2.

83. Leland Albright A, Barry MJ, Shafron DH, Ferson SS. Intrathecal baclofen for generalized dystonia. Developmental Medicine \& Child Neurology. 2001;43(10):652-7.

84. Albright AL. Intraventricular baclofen infusion for dystonia. Report of two cases. J Neurosurg. 2006;105(1 Suppl):71-4.

85. Turner M, Nguyen HS, Cohen-Gadol AA. Intraventricular baclofen as an alternative to intrathecal baclofen for intractable spasticity or dystonia: outcomes and technical considerations. J Neurosurg Pediatr. 2012;10(4):315-9.
86. Chuang C, Fahn S, Frucht SJ. The natural history and treatment of acquired hemidystonia: report of 33 cases and review of the literature. Journal of Neurology, Neurosurgery \& Psychiatry. 2002;72(1):59-67.

87. Daniele A, Albanese A, Gainotti G, Gregori B, Bartolomeo P. Zolpidem in Parkinson's disease. The Lancet. 1997;349(9060): 1222-3.

88. An JY, Kim J-S, Kim Y-I, Lee KS. Successful treatment of the Meige syndrome with oral zolpidem monotherapy. Movement Disorders. 2008;23(11):1619-21.

89. Evidente VGH. Zolpidem improves dystonia in "Lubag" or Xlinked dystonia-parkinsonism syndrome. NEUROLOGY. 2002;58(4):662-3.

90. Miyazaki Y, Sako W, Asanuma K, Izumi Y, Miki T, Kaji R. Efficacy of zolpidem for dystonia: a study among different subtypes. Frontiers in neurology. 2012;3:58.

91. Frucht SJ, Bordelon Y, Houghton WH, Reardan D. A pilot tolerability and efficacy trial of sodium oxybate in ethanol-responsive movement disorders. Movement Disorders. 2005;20(10):1330-7.

92. Mascia MM, Carmagnini D, Defazio G. Cannabinoids and dystonia: an issue yet to be defined. NEUROLOGICAL SCIENCES. 2020;41(4):783-7.

93. Consroe P, Sandyk R, Snider SR. Open label evaluation of cannabidiol in dystonic movement disorders. International Journal of Neuroscience. 1986;30(4):277-82.

94. Fox SH, Kellett M, Moore AP, Crossman AR, Brotchie JM. Randomised, double-blind, placebo-controlled trial to assess the potential of cannabinoid receptor stimulation in the treatment of dystonia. Mov Disord. 2002;17(1):145-9.

95. Zadikoff C, Wadia PM, Miyasaki J, Chen R, Lang AE, So J, et al. Cannabinoid, CB1 agonists in cervical dystonia: Failure in a phase IIa randomized controlled trial. Basal Ganglia. 2011;1(2):91-5.

96. Lucetti C, Nuti A, Gambaccini G, Bernardini S, Brotini S, Manca ML, et al. Mexiletine in the treatment of torticollis and generalized dystonia. Clin Neuropharmacol. 2000;23(4):186-9.

97. Park JE, Srivanitchapoom P, Maurer CW, Mathew P, Sackett J, Paine R, et al. Lack of efficacy of levetiracetam in oromandibular and cranial dystonia. Acta Neurol Scand. 2017;136(2):103-8.

98. Hainque E, Vidailhet M, Cozic N, Charbonnier-Beaupel F, Thobois S, Tranchant C, et al. A randomized, controlled, double-blind, crossover trial of zonisamide in myoclonus-dystonia. Neurology. 2016;86(18):1729-35.

99. Simpson DM, Hallett M, Ashman EJ, Comella CL, Green MW, Gronseth GS, et al. Practice guideline update summary: Botulinum neurotoxin for the treatment of blepharospasm, cervical dystonia, adult spasticity, and headache: Report of the Guideline Development Subcommittee of the American Academy of Neurology. Neurology. 2016;86(19):1818-26.

100. Comella CL, Buchman AS, Tanner CM, Brown-Toms NC, Goetz CG. Botulinum toxin injection for spasmodic torticollis: increased magnitude of benefit with electromyographic assistance. Neurology. 1992;42(4):878-82.

101. Jankovic J. Treatment of cervical dystonia with botulinum toxin. Mov Disord. 2004;19 Suppl 8:S109-15.

102. Duarte GS, Rodrigues FB, Ferreira JJ, Costa J. Adverse events with botulinum toxin treatment in cervical dystonia: How much should we blame placebo? Parkinsonism Relat Disord. 2018;56: 16-9.

103. Bhidayasiri R. Treatment of complex cervical dystonia with botulinum toxin: involvement of deep-cervical muscles may contribute to suboptimal responses. Parkinsonism Relat Disord. 2011;17 Suppl 1:S20-4.

104. Glass GA, Ku S, Ostrem JL, Heath S, Larson PS. Fluoroscopic, EMG-guided injection of botulinum toxin into the longus colli for the treatment of anterocollis. Parkinsonism Relat Disord. 2009; 15(8):610-3. 
105. Allison SK, Odderson IR. Ultrasound and Electromyography Guidance for Injection of the Longus Colli With Botulinum Toxin for the Treatment of Cervical Dystonia. Ultrasound Q. 2016;32(3):302-6.

106. Schramm A, Huber D, Mobius C, Munchau A, Kohl Z, Baumer T. Involvement of obliquus capitis inferior muscle in dystonic head tremor. Parkinsonism Relat Disord. 2017;44:119-23.

107. Walter U, Dudesek A, Fietzek UM. A simplified ultrasonographyguided approach for neurotoxin injection into the obliquus capitis inferior muscle in spasmodic torticollis. J Neural Transm (Vienna). 2018;125(7):1037-42.

108. Jankovic J, Truong D, Patel AT, Brashear A, Evatt M, Rubio RG, et al. Injectable DaxibotulinumtoxinA in Cervical Dystonia: A Phase 2 Dose-Escalation Multicenter Study. Mov Disord Clin Pract. 2018;5(3):273-82.

109. Prescribing Information: Xeomin ${ }^{\circledR}$. U.S. Food and Drug Administration website Frankfurt, Germany: Merz Pharmaceuticals, LLC; 2020 [updated May 2019. Available from: https://www.accessdata.fda.gov/drugsatfda_docs/label/2019/ 125360s074lbl.pdf.

110. Karp BI, Alter K. Botulinum Toxin Treatment of Blepharospasm, Orofacial/Oromandibular Dystonia, and Hemifacial Spasm. Semin Neurol. 2016;36(1):84-91.

111. Ozzello DJ, Giacometti JN. Botulinum Toxins for Treating Essential Blepharospasm and Hemifacial Spasm. Int Ophthalmol Clin. 2018;58(1):49-61.

112. Albanese A, Bentivoglio AR, Colosimo C, Galardi G, Maderna L, Tonali P. Pretarsal injections of botulinum toxin improve blepharospasm in previously unresponsive patients. J Neurol Neurosurg Psychiatry. 1996;60(6):693-4.

113. Tan EK, Jankovic J. Botulinum toxin A in patients with oromandibular dystonia: long-term follow-up. Neurology. 1999;53(9):2102-7.

114. Comella CL. Systematic review of botulinum toxin treatment for oromandibular dystonia. Toxicon. 2018;147:96-9.

115. Moscovich M, Chen ZP, Rodriguez R. Successful treatment of open jaw and jaw deviation dystonia with botulinum toxin using a simple intraoral approach. J Clin Neurosci. 2015;22(3):594-6.

116. Scorr LM, Silver MR, Hanfelt J, Sperin E, Freeman A, Jinnah HA, et al. Pilot Single-Blind Trial of AbobotulinumtoxinA in Oromandibular Dystonia. Neurotherapeutics. 2018;15(2):452-8.

117. Blitzer A. Spasmodic dysphonia and botulinum toxin: experience from the largest treatment series. Eur J Neurol. 2010;17 Suppl 1: 28-30.

118. Payne S, Tisch S, Cole I, Brake H, Rough J, Darveniza P. The clinical spectrum of laryngeal dystonia includes dystonic cough: observations of a large series. Mov Disord. 2014;29(6):729-35.

119. Blitzer A, Brin MF, Fahn S, Lovelace RE. Localized injections of botulinum toxin for the treatment of focal laryngeal dystonia (spastic dysphonia). Laryngoscope. 1988;98(2):193-7.

120. Troung DD, Rontal M, Rolnick M, Aronson AE, Mistura K. Double-blind controlled study of botulinum toxin in adductor spasmodic dysphonia. Laryngoscope. 1991;101(6 Pt 1):630-4.

121. Tierney WS, Bryson PC, Nelson R, Kaplan SE, Benninger MS, Milstein CF. Respiratory Laryngeal Dystonia: Characterization and Diagnosis of a Rare Neurogenic Disorder. Laryngoscope. 2020.

122. Woisard V, Liu X, Bes MC, Simonetta-Moreau M. Botulinum toxin injection in laryngeal dyspnea. Eur Arch Otorhinolaryngol. 2017;274(2):909-17.

123. Hallett M, Benecke R, Blitzer A, Comella CL. Treatment of focal dystonias with botulinum neurotoxin. Toxicon. 2009;54(5):62833.

124. Lungu C, Karp BI, Alter K, Zolbrod R, Hallett M. Long-term follow-up of botulinum toxin therapy for focal hand dystonia: outcome at 10 years or more. Mov Disord. 2011;26(4):750-3.
125. Kruisdijk JJ, Koelman JH, Ongerboer de Visser BW, de Haan RJ, Speelman JD. Botulinum toxin for writer's cramp: a randomised, placebo-controlled trial and 1-year follow-up. J Neurol Neurosurg Psychiatry. 2007;78(3):264-70.

126. Tsui JK, Bhatt M, Calne S, Calne DB. Botulinum toxin in the treatment of writer's cramp: a double-blind study. Neurology. 1993;43(1):183-5.

127. Cole R, Hallett M, Cohen LG. Double-blind trial of botulinum toxin for treatment of focal hand dystonia. Mov Disord. 1995;10(4):466-71.

128. Yoshimura DM, Aminoff MJ, Olney RK. Botulinum toxin therapy for limb dystonias. Neurology. 1992;42(3 Pt 1):627-30.

129. Schuele S, Jabusch HC, Lederman RJ, Altenmuller E. Botulinum toxin injections in the treatment of musician's dystonia. Neurology. 2005;64(2):341-3.

130. Marion MH, Afors K, Sheehy MP. Problems of treating writer's cramp with botulinum toxin injections: results from 10 years of experience. Rev Neurol (Paris). 2003;159(10 Pt 1):923-7.

131. Molloy FM, Shill HA, Kaelin-Lang A, Karp BI. Accuracy of muscle localization without EMG: implications for treatment of limb dystonia. Neurology. 2002;58(5):805-7.

132. Rieu I, Degos B, Castelnovo G, Vial C, Durand E, Pereira B, et al. Incobotulinum toxin A in Parkinson's disease with foot dystonia: A double blind randomized trial. Parkinsonism Relat Disord. 2018;46:9-15.

133. Gupta AD, Visvanathan R. Botulinum toxin for foot dystonia in patients with Parkinson's disease having deep brain stimulation: A case series and a pilot study. J Rehabil Med. 2016;48(6):559-62.

134. Datta Gupta A, Tucker G, Koblar S, Visvanathan R, Cameron ID. Spatiotemporal Gait Analysis and Lower Limb Functioning in Foot Dystonia Treated with Botulinum Toxin. Toxins (Basel). 2018;10(12).

135. Schneider SA, Edwards MJ, Grill SE, Goldstein S, Kanchana S, Quinn NP, et al. Adult-onset primary lower limb dystonia. Mov Disord. 2006;21(6):767-71.

136. Katz M, Byl NN, San Luciano M, Ostrem JL. Focal task-specific lower extremity dystonia associated with intense repetitive exercise: a case series. Parkinsonism Relat Disord. 2013;19(11):10338.

137. Cooper I. 20-year follow-up study of the neurosurgical treatment of dystonia musculorum deformans. In: Eldridge R FS, editor. Dystonia: Advances in Neurology. New York: Raven Press; 1976. p. 423-52.

138. Andrew J, Fowler CJ, Harrison MJ. Stereotaxic thalamotomy in 55 cases of dystonia. Brain. 1983;106 ( Pt 4):981-1000.

139. Gros C, Frerebeau P, Perez-Dominguez E, Bazin M, Privat J. Long term results of stereotaxic surgery for infantile dystonia and dyskinesia. Neurochirurgia (Stuttg). 1976;19:171-8.

140. Tasker RR, Doorly T, Yamashiro K. Thalamotomy in generalized dystonia. In: Fahn S, Marsden CD, Calne DB, editors. Dystonia 2: Advances in Neurology. New York: Raven Press; 1988. p. 61531.

141. Broggi G, Angelini L, Giorgi C. Neurological and psychological side effects after stereotactic thalamotomy in patients with cerebral palsy. Neurosurgery. 1980;7(2):127-34.

142. Broggi G, Angelini L, Bono R, Giorgi C, Nardocci N, Franzini A. Long term results of stereotactic thalamotomy for cerebral palsy. Neurosurgery. 1983;12(2):195-202.

143. Krack P, Vercueil L. Review of the functional surgical treatment of dystonia. Eur J Neurol. 2001;8(5):389-99.

144. Cardoso F, Jankovic J, Grossman RG, Hamilton WJ. Outcome after stereotactic thalamotomy for dystonia and hemiballismus. Neurosurgery. 1995;36(3):501-7; discussion 7-8.

145. Ondo WG, Desaloms JM, Jankovic J, Grossman RG. Pallidotomy for generalized dystonia. Mov Disord. 1998;13(4):693-8. 
146. Lin JJ, Lin SZ, Chang DC. Pallidotomy and generalized dystonia. Mov Disord. 1999;14(6):1057-9.

147. Gross RE. What happened to posteroventral pallidotomy for Parkinson's disease and dystonia? Neurotherapeutics. 2008;5(2): 281-93.

148. Ostrem JL, Starr PA. Treatment of dystonia with deep brain stimulation. Neurotherapeutics. 2008;5(2):320-30.

149. Shimizu T, Maruo T, Miura S, Kishima H, Ushio Y, Goto S. Stereotactic Lesioning of the Thalamic Vo Nucleus for the Treatment of Writer's Cramp (Focal Hand Dystonia). Front Neurol. 2018;9:1008.

150. Horisawa S, Ochiai T, Goto S, Nakajima T, Takeda N, Fukui A, et al. Safety and long-term efficacy of ventro-oral thalamotomy for focal hand dystonia: A retrospective study of 171 patients. Neurology. 2019;92(4):e371-e7.

151. Cury RG, Kalia SK, Shah BB, Jimenez-Shahed J, Prashanth LK, Moro E. Surgical treatment of dystonia. Expert Rev Neurother. 2018;18(6):477-92.

152. Fishman PS, Frenkel V. Treatment of Movement Disorders With Focused Ultrasound. J Cent Nerv Syst Dis. 2017;9: 1179573517705670.

153. Krishna V, Sammartino F, Rezai A. A Review of the Current Therapies, Challenges, and Future Directions of Transcranial Focused Ultrasound Technology: Advances in Diagnosis and Treatment. JAMA Neurol. 2018;75(2):246-54.

154. Fasano A, Llinas M, Munhoz RP, Hlasny E, Kucharczyk W, Lozano AM. MRI-guided focused ultrasound thalamotomy in non-ET tremor syndromes. Neurology. 2017;89(8):771-5.

155. Horisawa S, Yamaguchi T, Abe K, Hori H, Sumi M, Konishi Y, et al. A single case of MRI-guided focused ultrasound ventro-oral thalamotomy for musician's dystonia. J Neurosurg. 2018;131(2): 384-6.

156. Kupsch A, Benecke R, Muller J, Trottenberg T, Schneider GH, Poewe $\mathrm{W}$, et al. Pallidal deep-brain stimulation in primary generalized or segmental dystonia. N Engl J Med. 2006;355(19):197890.

157. Vidailhet M, Vercueil L, Houeto JL, Krystkowiak P, Lagrange C, Yelnik J, et al. Bilateral, pallidal, deep-brain stimulation in primary generalised dystonia: a prospective 3 year follow-up study. Lancet Neurol. 2007;6(3):223-9.

158. Volkmann J, Mueller J, Deuschl G, Kuhn AA, Krauss JK, Poewe $\mathrm{W}$, et al. Pallidal neurostimulation in patients with medicationrefractory cervical dystonia: a randomised, sham-controlled trial. Lancet Neurol. 2014;13(9):875-84.

159. Isaias IU, Alterman RL, Tagliati M. Outcome predictors of pallidal stimulation in patients with primary dystonia: the role of disease duration. Brain. 2008;131(Pt 7):1895-902.

160. Volkmann J, Wolters A, Kupsch A, Muller J, Kuhn AA, Schneider GH, et al. Pallidal deep brain stimulation in patients with primary generalised or segmental dystonia: 5-year follow-up of a randomised trial. Lancet Neurol. 2012;11(12):1029-38.

161. Bruggemann N, Kuhn A, Schneider SA, Kamm C, Wolters A, Krause P, et al. Short- and long-term outcome of chronic pallidal neurostimulation in monogenic isolated dystonia. Neurology. 2015;84(9):895-903.

162. Contarino MF, Smit M, van den Dool J, Volkmann J, Tijssen MA. Unmet Needs in the Management of Cervical Dystonia. Frontiers in neurology. 2016;7:165.

163. Tagliati M, Krack P, Volkmann J, Aziz T, Krauss JK, Kupsch A, et al. Long-Term management of DBS in dystonia: Response to stimulation, adverse events, battery changes, and special considerations. Movement Disorders. 2011;26(S1):S54-S62.

164. Lee DJ, Lozano CS, Dallapiazza RF, Lozano AM. Current and future directions of deep brain stimulation for neurological and psychiatric disorders. J Neurosurg. 2019;131(2):333-42.
165. Mueller J, Skogseid IM, Benecke R, Kupsch A, Trottenberg T, Poewe W, et al. Pallidal deep brain stimulation improves quality of life in segmental and generalized dystonia: Results from a prospective, randomized sham-controlled trial. Movement Disorders. 2008;23(1):131-4.

166. Vidailhet M, Vercueil L, Houeto JL, Krystkowiak P, Benabid AL, Cornu P, et al. Bilateral deep-brain stimulation of the globus pallidus in primary generalized dystonia. $\mathrm{N}$ Engl $\mathrm{J}$ Med. 2005;352(5):459-67.

167. Reese R, Gruber D, Schoenecker T, Bazner H, Blahak C, Capelle $\mathrm{HH}$, et al. Long-term clinical outcome in meige syndrome treated with internal pallidum deep brain stimulation. Mov Disord. 2011;26(4):691-8.

168. Ostrem JL, Marks WJ, Jr., Volz MM, Heath SL, Starr PA. Pallidal deep brain stimulation in patients with cranial-cervical dystonia (Meige syndrome). Mov Disord. 2007;22(13):1885-91.

169. Wang X, Zhang Z, Mao Z, Yu X. Deep brain stimulation for Meige syndrome: a meta-analysis with individual patient data. $\mathrm{J}$ Neurol. 2019;266(11):2646-56.

170. Trottenberg T, Volkmann J, Deuschl G, Kühn AA, Schneider G$\mathrm{H}$, Müller J, et al. Treatment of severe tardive dystonia with pallidal deep brain stimulation. Neurology. 2005;64(2):344-6.

171. Pouclet-Courtemanche H, Rouaud T, Thobois S, Nguyen J-m, Brefel-Courbon C, Chereau I, et al. Long-term efficacy and tolerability of bilateral pallidal stimulation to treat tardive dyskinesia. Neurology. 2016;86.

172. Gruber D, Südmeyer M, Deuschl G, Falk D, Krauss JK, Mueller J, et al. Neurostimulation in tardive dystonia/dyskinesia: A delayed start, sham stimulation-controlled randomized trial. Brain Stimul. 2018;11(6):1368-77.

173. Jinnah HA. Medical and Surgical Treatments for Dystonia. Neurol Clin. 2020;38(2):325-48.

174. Jinnah HA, Alterman R, Klein C, Krauss JK, Moro E, Vidailhet $\mathrm{M}$, et al. Deep brain stimulation for dystonia: a novel perspective on the value of genetic testing. J Neural Transm (Vienna). 2017;124(4):417-30.

175. Reich MM, Horn A, Lange F, Roothans J, Paschen S, Runge J, et al. Probabilistic mapping of the antidystonic effect of pallidal neurostimulation: a multicentre imaging study. Brain. 2019;142(5):1386-98.

176. Ostrem JL, Racine CA, Glass GA, Grace JK, Volz MM, Heath SL, et al. Subthalamic nucleus deep brain stimulation in primary cervical dystonia. Neurology. 2011;76(10):870-8.

177. Ostrem JL, San Luciano M, Dodenhoff KA, Ziman N, Markun LC, Racine CA, et al. Subthalamic nucleus deep brain stimulation in isolated dystonia: A 3-year follow-up study. Neurology. 2017;88(1):25-35.

178. Hedera P, Phibbs FT, Dolhun R, Charles PD, Konrad PE, Neimat JS, et al. Surgical targets for dystonic tremor: Considerations between the globus pallidus and ventral intermediate thalamic nucleus. Parkinsonism \& Related Disorders. 2013;19(7):684-6.

179. Fasano A, Bove F, Lang AE. The treatment of dystonic tremor: a systematic review. J Neurol Neurosurg Psychiatry. 2014;85(7): 759-69.

180. Tierney TS, Lozano AM. Surgical treatment for secondary dystonia. Mov Disord. 2012;27(13):1598-605.

181. Koy A, Hellmich M, Pauls KA, Marks W, Lin JP, Fricke O, et al. Effects of deep brain stimulation in dyskinetic cerebral palsy: a meta-analysis. Mov Disord. 2013;28(5):647-54.

182. Patel A, Deeb W, Okun MS. Deep Brain Stimulation Management of Essential Tremor with Dystonic Features. Tremor Other Hyperkinet Mov (N Y). 2018;8:557.

183. Sanger TD, Liker M, Arguelles E, Deshpande R, Maskooki A, Ferman D, et al. Pediatric Deep Brain Stimulation Using Awake Recording and Stimulation for Target Selection in an Inpatient Neuromodulation Monitoring Unit. Brain Sci. 2018;8(7). 
184. Wolf ME, Blahak C, Saryyeva A, Schrader C, Krauss JK. Deep brain stimulation for dystonia-choreoathetosis in cerebral palsy: Pallidal versus thalamic stimulation. Parkinsonism Relat Disord. 2019;63:209-12.

185. Brown EG, Bledsoe IO, Luthra NS, Miocinovic S, Starr PA, Ostrem JL. Cerebellar Deep Brain Stimulation for Acquired Hemidystonia. Mov Disord Clin Pract. 2020;7(2):188-93.

186. Starr PA, Turner RS, Rau G, Lindsey N, Heath S, Volz M, et al. Microelectrode-guided implantation of deep brain stimulators into the globus pallidus internus for dystonia: techniques, electrode locations, and outcomes. J Neurosurg. 2006;104(4):488-501.

187. Videnovic A, Metman LV. Deep brain stimulation for Parkinson's disease: prevalence of adverse events and need for standardized reporting. Mov Disord. 2008;23(3):343-9.

188. Panov F, Gologorsky Y, Connors G, Tagliati M, Miravite J, Alterman RL. Deep brain stimulation in DYT1 dystonia: a 10year experience. Neurosurgery. 2013;73(1):86-93; discussion

189. Zauber SE, Watson N, Comella CL, Bakay RA, Metman LV. Stimulation-induced parkinsonism after posteroventral deep brain stimulation of the globus pallidus internus for craniocervical dystonia. J Neurosurg. 2009;110(2):229-33.

190. Berman BD, Starr PA, Marks WJ, Jr., Ostrem JL. Induction of bradykinesia with pallidal deep brain stimulation in patients with cranial-cervical dystonia. Stereotact Funct Neurosurg. 2009;87(1): $37-44$

191. Starr PA, Markun LC, Larson PS, Volz MM, Martin AJ, Ostrem JL. Interventional MRI-guided deep brain stimulation in pediatric dystonia: first experience with the ClearPoint system. J Neurosurg Pediatr. 2014;14(4):400-8.

192. Krack P, Volkmann J, Tinkhauser G, Deuschl G. Deep Brain Stimulation in Movement Disorders: From Experimental Surgery to Evidence-Based Therapy. Mov Disord. 2019;34(12): 1795-810.

193. Pina-Fuentes D, Little S, Oterdoom M, Neal S, Pogosyan A, Tijssen MAJ, et al. Adaptive DBS in a Parkinson's patient with chronically implanted DBS: A proof of principle. Mov Disord. 2017;32(8):1253-4.

194. Neumann WJ, Huebl J, Brucke C, Ruiz MH, Kupsch A, Schneider $\mathrm{GH}$, et al. Enhanced low-frequency oscillatory activity of the subthalamic nucleus in a patient with dystonia. Mov Disord. 2012;27(8):1063-6.

195. Silberstein P, Kuhn AA, Kupsch A, Trottenberg T, Krauss JK, Wohrle JC, et al. Patterning of globus pallidus local field potentials differs between Parkinson's disease and dystonia. Brain. 2003;126(Pt 12):2597-608.

196. Siebner HR, Tormos JM, Ceballos-Baumann AO, Auer C, Catala $\mathrm{MD}$, Conrad B, et al. Low-frequency repetitive transcranial magnetic stimulation of the motor cortex in writer's cramp. Neurology. 1999;52(3):529-37.

197. Murase N, Rothwell JC, Kaji R, Urushihara R, Nakamura K, Murayama N, et al. Subthreshold low-frequency repetitive transcranial magnetic stimulation over the premotor cortex modulates writer's cramp. Brain. 2005;128(Pt 1):104-15.

198. Borich M, Arora S, Kimberley TJ. Lasting effects of repeated rTMS application in focal hand dystonia. Restor Neurol Neurosci. 2009;27(1):55-65.

199. Veugen LC, Hoffland BS, Stegeman DF, van de Warrenburg BP. Inhibition of the dorsal premotor cortex does not repair surround inhibition in writer's cramp patients. Exp Brain Res. 2013;225(1): 85-92.

200. Siebner HR, Filipovic SR, Rowe JB, Cordivari C, Gerschlager W, Rothwell JC, et al. Patients with focal arm dystonia have increased sensitivity to slow-frequency repetitive TMS of the dorsal premotor cortex. Brain. 2003;126(Pt 12):2710-25.

201. Kimberley TJ, Borich MR, Arora S, Siebner HR. Multiple sessions of low-frequency repetitive transcranial magnetic stimulation in focal hand dystonia: clinical and physiological effects. Restor Neurol Neurosci. 2013;31(5):533-42.

202. Havrankova P, Jech R, Walker ND, Operto G, Tauchmanova J, Vymazal J, et al. Repetitive TMS of the somatosensory cortex improves writer's cramp and enhances cortical activity. Neuro Endocrinol Lett. 2010;31(1):73-86.

203. Linssen MW, van Gaalen J, Munneke MA, Hoffland BS, Hulstijn W, van de Warrenburg BP. A single session of cerebellar theta burst stimulation does not alter writing performance in writer's cramp. Brain. 2015;138(Pt 6):e355.

204. Koch G, Porcacchia P, Ponzo V, Carrillo F, Caceres-Redondo MT, Brusa L, et al. Effects of two weeks of cerebellar theta burst stimulation in cervical dystonia patients. Brain Stimul. 2014;7(4): 564-72.

205. Pirio Richardson S, Tinaz S, Chen R. Repetitive transcranial magnetic stimulation in cervical dystonia: effect of site and repetition in a randomized pilot trial. PLoS One. 2015;10(4):e0124937.

206. Zittel S, Helmich RC, Demiralay C, Munchau A, Baumer T. Normalization of sensorimotor integration by repetitive transcranial magnetic stimulation in cervical dystonia. J Neurol. 2015;262(8):1883-9.

207. Kranz G, Shamim EA, Lin PT, Kranz GS, Hallett M. Transcranial magnetic brain stimulation modulates blepharospasm: a randomized controlled study. Neurology. 2010;75(16):1465-71.

208. Sharma K, Cucca A, Lee A, Agarwal S, Frucht SJ, Biagioni MC. Transcranial magnetic stimulation therapy for focal leg dystonia: a case report. J Clin Mov Disord. 2019;6:1.

209. Buttkus F, Weidenmuller M, Schneider S, Jabusch HC, Nitsche MA, Paulus W, et al. Failure of cathodal direct current stimulation to improve fine motor control in musician's dystonia. Mov Disord. 2010;25(3):389-94.

210. Buttkus F, Baur V, Jabusch HC, de la Cruz Gomez-Pellin M, Paulus W, Nitsche MA, et al. Single-session tDCS-supported retraining does not improve fine motor control in musician's dystonia. Restor Neurol Neurosci. 2011;29(2):85-90.

211. Benninger DH, Lomarev M, Lopez G, Pal N, Luckenbaugh DA, Hallett M. Transcranial direct current stimulation for the treatment of focal hand dystonia. Mov Disord. 2011;26(9):1698-702.

212. Sadnicka A, Hamada M, Bhatia KP, Rothwell JC, Edwards MJ. Cerebellar stimulation fails to modulate motor cortex plasticity in writing dystonia. Mov Disord. 2014;29(10):1304-7.

213. Rosset-Llobet J, Fabregas-Molas S, Pascual-Leone A. Effect of Transcranial Direct Current Stimulation on Neurorehabilitation of Task-Specific Dystonia: A Double-Blind, Randomized Clinical Trial. Med Probl Perform Art. 2015;30(3):178-84.

214. Furuya S, Nitsche MA, Paulus W, Altenmuller E. Surmounting retraining limits in musicians' dystonia by transcranial stimulation. Ann Neurol. 2014;75(5):700-7.

215. Bradnam LV, Graetz LJ, McDonnell MN, Ridding MC. Anodal transcranial direct current stimulation to the cerebellum improves handwriting and cyclic drawing kinematics in focal hand dystonia. Front Hum Neurosci. 2015;9:286.

216. Angelakis E, Liouta E, Andreadis N, Leonardos A, Ktonas P, Stavrinou LC, et al. Transcranial alternating current stimulation reduces symptoms in intractable idiopathic cervical dystonia: a case study. Neurosci Lett. 2013;533:39-43.

217. Khosravani S, Mahnan A, Yeh IL, Aman JE, Watson PJ, Zhang Y, et al. Laryngeal vibration as a non-invasive neuromodulation therapy for spasmodic dysphonia. Sci Rep. 2019;9(1):17955.

218. Prudente CN, Zetterberg L, Bring A, Bradnam L, Kimberley TJ. Systematic Review of Rehabilitation in Focal Dystonias: Classification and Recommendations. Mov Disord Clin Pract. 2018;5(3):237-45

219. Guyatt GH, Oxman AD, Vist GE, Kunz R, Falck-Ytter Y, AlonsoCoello P, et al. GRADE: an emerging consensus on rating quality 
of evidence and strength of recommendations. BMJ. 2008;336(7650):924-6.

220. Pirio Richardson S, Altenmuller E, Alter K, Alterman RL, Chen R, Frucht S, et al. Research Priorities in Limb and Task-Specific Dystonias. Front Neurol. 2017;8:170.

221. Priori A, Pesenti A, Cappellari A, Scarlato G, Barbieri S. Limb immobilization for the treatment of focal occupational dystonia. Neurology. 2001;57(3):405-9.

222. Candia V, Schafer T, Taub E, Rau H, Altenmuller E, Rockstroh B, et al. Sensory motor retuning: a behavioral treatment for focal hand dystonia of pianists and guitarists. Arch Phys Med Rehabil. 2002;83(10):1342-8.

223. Candia V, Elbert T, Altenmuller E, Rau H, Schafer T, Taub E. Constraint-induced movement therapy for focal hand dystonia in musicians. Lancet. 1999;353(9146):42.

224. Berque P, Gray H, Harkness C, McFadyen A. A combination of constraint-induced therapy and motor control retraining in the treatment of focal hand dystonia in musicians. Med Probl Perform Art. 2010;25(4):149-61.

225. Zeuner KE, Shill HA, Sohn YH, Molloy FM, Thornton BC, Dambrosia JM, et al. Motor training as treatment in focal hand dystonia. Mov Disord. 2005;20(3):335-41.

226. Candia V, Wienbruch C, Elbert T, Rockstroh B, Ray W. Effective behavioral treatment of focal hand dystonia in musicians alters somatosensory cortical organization. Proc Natl Acad Sci U S A. 2003;100(13):7942-6.

227. Rosset-Llobet J, Fabregas-Molas S. Long-term treatment effects of sensory motor retuning in a pianist with focal dystonia. Med Probl Perform Art. 2011;26(2):106-7.

228. Sakai N. Slow-down exercise for the treatment of focal hand dystonia in pianists. Med Probl Perform Art. 2006;21(1):25-8.

229. Hinkley LB, Webster RL, Byl NN, Nagarajan SS. Neuroimaging characteristics of patients with focal hand dystonia. J Hand Ther. 2009;22(2):125-34; quiz 35.

230. Byl NN, Archer ES, McKenzie A. Focal hand dystonia: effectiveness of a home program of fitness and learning-based sensorimotor and memory training. J Hand Ther. 2009;22(2):183-97; quiz 98.

231. Zeuner KE, Bara-Jimenez W, Noguchi PS, Goldstein SR, Dambrosia JM, Hallett M. Sensory training for patients with focal hand dystonia. Ann Neurol. 2002;51(5):593-8.

232. Zeuner KE, Hallett M. Sensory training as treatment for focal hand dystonia: a 1-year follow-up. Mov Disord. 2003;18(9):1044-7.

233. Byl NN, McKenzie A. Treatment effectiveness for patients with a history of repetitive hand use and focal hand dystonia: a planned, prospective follow-up study. J Hand Ther. 2000;13(4):289-301.

234. Bleton JP, Vidailhet M, Bourdain F, Ducorps A, Schwartz D, Delmaire C, et al. Somatosensory cortical remodelling after rehabilitation and clinical benefit of in writer's cramp. J Neurol Neurosurg Psychiatry. 2011;82(5):574-7.

235. Enke AM, Poskey GA. Neuromuscular Re-Education Programs for Musicians with Focal Hand Dystonia: A Systematic Review. Med Probl Perform Art. 2018;33(2):137-45.

236. Berque $\mathrm{P}$, Gray $\mathrm{H}, \mathrm{McFadyen} \mathrm{A}$. A combination of constraintinduced therapy and motor control retraining in the treatment of focal hand dystonia in musicians: a long-term follow-up study. Med Probl Perform Art. 2013;28(1):33-46.

237. McKenzie AL, Goldman S, Barrango C, Shrime M, Wong T, Byl N. Differences in physical characteristics and response to rehabilitation for patients with hand dystonia: musicians' cramp compared to writers' cramp. J Hand Ther. 2009;22(2):172-81; quiz 82.

238. Yoshie M, Sakai N, Ohtsuki T, Kudo K. Slow-down exercise reverses sensorimotor reorganization in focal hand dystonia: a case study of a pianist. Int J Neurorehabilitation. 2015;2(2): 2376-0281.100015.

239. Jahanshahi M, Sartory G, Marsden CD. EMG biofeedback treatment of torticollis: a controlled outcome study. Biofeedback Self Regul. 1991;16(4):413-48.

240. Duddy J, McLellan D. Lack of influence of EMG biofeedback in relaxation training for spasmodic torticollis. Clinical rehabilitation. 1995;9(4):297-303.

241. Boyce MJ, Canning CG, Mahant N, Morris J, Latimer J, Fung VS. Active exercise for individuals with cervical dystonia: a pilot randomized controlled trial. Clin Rehabil. 2013;27(3):226-35.

242. Tassorelli C, Mancini F, Balloni L, Pacchetti C, Sandrini G, Nappi $\mathrm{G}$, et al. Botulinum toxin and neuromotor rehabilitation: An integrated approach to idiopathic cervical dystonia. Mov Disord. 2006;21(12):2240-3.

243. El-Bahrawy MN, El-Tamawy MS, Shalaby NM, Abdel-Alim AM. Cervical dystonia: Abnormal head posture and its relation to hand function. Egypt J Neurol, Psychiatr Neurosurg. 2009;46: 203-8.

244. Hu W, Rundle-Gonzalez V, Kulkarni SJ, Martinez-Ramirez D, Almeida L, Okun MS, et al. A randomized study of botulinum toxin versus botulinum toxin plus physical therapy for treatment of cervical dystonia. Parkinsonism Relat Disord. 2019;63:195-8.

245. Queiroz MA, Chien HF, Sekeff-Sallem FA, Barbosa ER. Physical therapy program for cervical dystonia: a study of 20 cases. Funct Neurol. 2012;27(3):187-92.

246. van den Dool J, Visser B, Koelman JH, Engelbert RH, Tijssen MA. Long-Term Specialized Physical Therapy in Cervical Dystonia: Outcomes of a Randomized Controlled Trial. Arch Phys Med Rehabil. 2019;100(8):1417-25.

Publisher's Note Springer Nature remains neutral with regard to jurisdictional claims in published maps and institutional affiliations. 